Provided for non-commercial research and education use. Not for reproduction, distribution or commercial use.

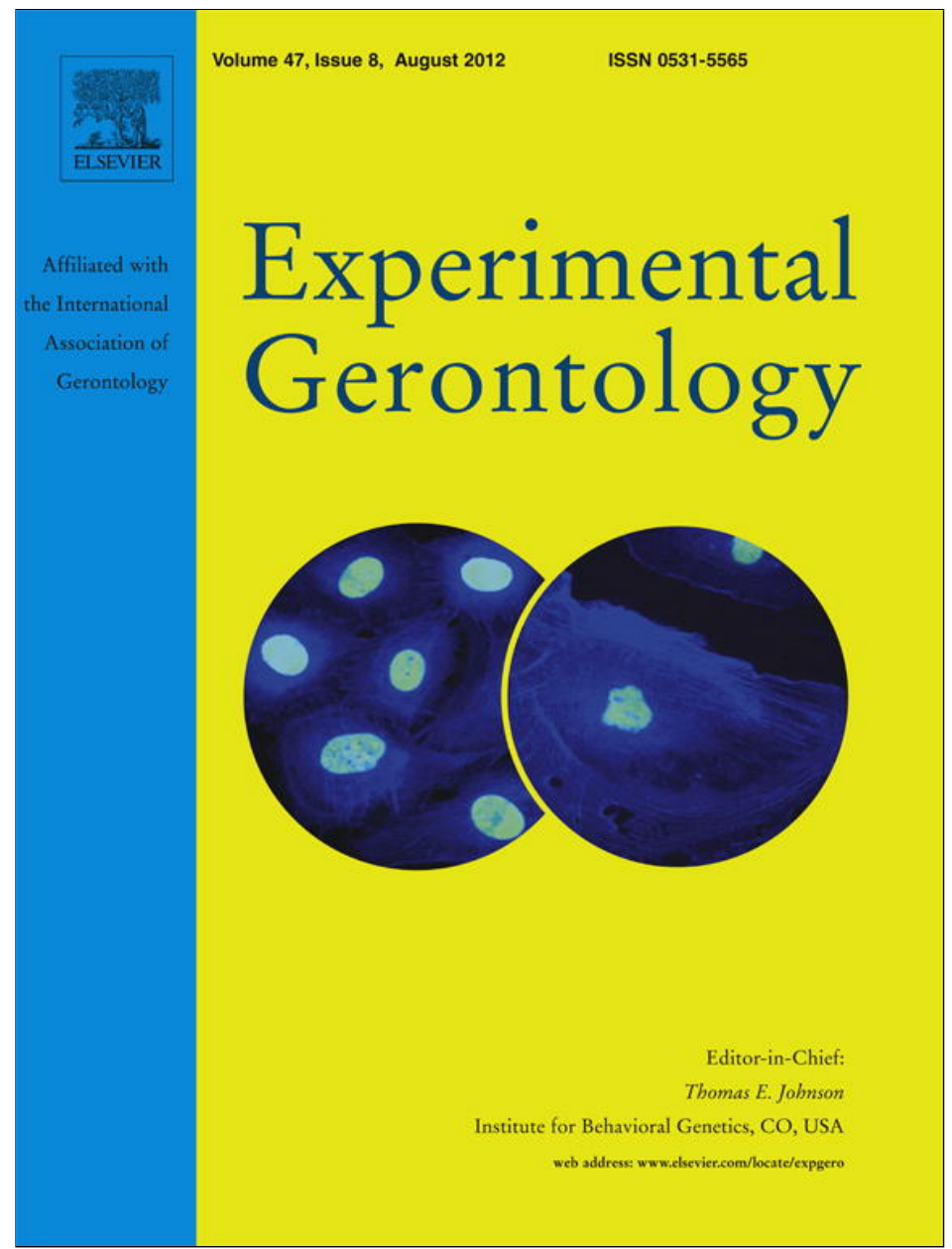

This article appeared in a journal published by Elsevier. The attached copy is furnished to the author for internal non-commercial research and education use, including for instruction at the authors institution and sharing with colleagues.

Other uses, including reproduction and distribution, or selling or licensing copies, or posting to personal, institutional or third party websites are prohibited.

In most cases authors are permitted to post their version of the article (e.g. in Word or Tex form) to their personal website or institutional repository. Authors requiring further information regarding Elsevier's archiving and manuscript policies are encouraged to visit:

http://www.elsevier.com/copyright 


\title{
Anhedonic-like traits and lack of affective deficits in 18-month-old C57BL/6 mice: Implications for modeling elderly depression
}

\author{
Ewa Malatynska a , Harry W.M. Steinbusch ${ }^{\text {b }}$, Olga Redkozubova ${ }^{c}$, Alexei Bolkunov ${ }^{c}$, Aslan Kubatiev ${ }^{\mathrm{d}}$, \\ Naira B. Yeritsyan ${ }^{\text {e, Julie Vignisse }}{ }^{\text {b }}$, Sergei Bachurin ${ }^{\text {c }}$, Tatyana Strekalova ${ }^{\text {b,* }}$ \\ ${ }^{a}$ Lilly Research Labs/Lilly Corporate Center, Delaware St., Indianapolis 839 S, IN 46225 USA \\ ${ }^{\mathrm{b}}$ School for Mental Health and Neuroscience, Department of Neuroscience, Maastricht University, Universiteitssingel 50, NL 6229 ER Maastricht, The Netherlands \\ ${ }^{\mathrm{c}}$ Institute of Physiologically Active Compounds, Russian Academy of Sciences, Chernogolovka, Severnii proesd 1, 142432 Moscow Region, Russia \\ d Institute of General Pathology and Pathophysiology, Russian Academy of Medical Sciences, Baltyiskaia 8, 125315 Moscow, Russia \\ e Department of Neurophysiology, Leibniz Institute of Neurobiology, Center of Learning and Memory Research, Brenneckestrasse 6, 39118 Magdeburg, Germany
}

\section{A R T I C L E I N F O}

\section{Article history:}

Received 12 September 2011

Received in revised form 19 April 2012

Accepted 20 April 2012

Available online 11 May 2012

Section Editor: Christian Humpel

\section{Keywords:}

Elderly depression

Anhedonia

Behavioral despair

Sucrose test

Imipramine

Dimebon

Mouse

\begin{abstract}
A B S T R A C T
The prevalence of depression increases with aging. We hypothesized that like humans, old animals exhibit anhedonic-like behavior, along with signs of behavioral despair. In rodents, anhedonia, a reduced sensitivity to reward, which is listed as a core feature of major depression in the DSM-IVR, can be measured by a decrease in intake of and preference for sweet solutions. Here, sucrose intake, forced swimming, immobility in the modified tail suspension test, novelty exploration, grooming, anxiety and locomotor activity were compared in naïve 3- and 18-month-old male C57BL/6 mice. The absolute amounts and the ratio of consumed $1 \%$ sucrose solution to water intake was significantly smaller in 18-month-old mice than in 3-month-old mice. The consumption of 5\%-sucrose solution requiring high levels of drinking effort, novelty exploration in two setups and grooming behavior in the splash test were reduced in older animals. Analysis of other behaviors suggested that the above-mentioned signs of anhedonic-like traits were unlikely to be attributable to the potential effect of aging on metabolic needs for water, taste perception, motor capabilities or the induction of essential anxiety and neophobia. A 4-week treatment with the antidepressant imipramine ( $7 \mathrm{mg} / \mathrm{kg} / \mathrm{day})$ or dimebon, a compound with suggested neuroprotective proneurogenic properties ( $1 \mathrm{mg} / \mathrm{kg} / \mathrm{day}$ ) restored sucrose intake and preference in 18-month-old mice. Meanwhile, young and old mice showed no differences in the parameters of behavioral despair evaluated in the forced swim and modified tail suspension tests. Thus, the behavioral profile of aged mice parallels that of humans with elderly depression, in whom the symptoms of hedonic deficits typically outweigh affective disturbances. The assessment of anhedonic-like traits with the sucrose preference test in 18-month-old mice will be useful in preclinical studies of elderly depression.
\end{abstract}

(c) 2012 Elsevier Inc. All rights reserved.

\section{Introduction}

The prevalence of depression is elevated in older people (Zanni and Wick, 2010; Glaesmer et al., 2011). The overall aging of the population suggests an increase in the social impact of elderly-related depressive disorders (Solhaug et al., 2011). According to the DSM-IVR, the cardinal symptom of major depression is clinically observed anhedonia, the decreased ability to experience pleasure, which is observed along with subsidiary features including affective disturbances (Hamilton, 1967; Klein, 1974). We hypothesized that old mice, like humans, exhibit anhedoniclike features and signs of behavioral despair when compared to younger animals and that these changes are sensitive to antidepressant treatment.

\footnotetext{
* Corresponding author at: Department of Neuroscience, Maastricht University, Universiteitssingel 40, NL 6229 ER Maastricht, The Netherlands. Tel.: +31 433884 110; fax: + 31433671096 .

E-mail address: t.strekalova@maastrichtuniversity.nl (T. Strekalova).
}

Both features of a depressive-like state are likely to occur in parallel (Fonken et al., 2009; Snyder et al., 2011). For example, anhedonia-like behavior defined by a decrease in sucrose intake and preference in chronically stressed C57BL/6N mice accompanies an increase in floating during forced swimming and immobility behavior in the modified tail suspension test (Strekalova et al., 2004; Strekalova and Steinbusch, 2010; Kanarik et al., 2011). These changes are often associated with a reduction in novelty exploration and grooming behavior in the splash test (Strekalova et al., 2004; Skrinskaia and Nikulina, 1994; Pothion et al., 2004). Antidepressant treatment counteracts the above-mentioned depressive-like traits in rodents (Porsolt and Papp, 1998; Willner, 2005; Strekalova et al., 2011; Yacoubi et al., 2011; Surget et al., 2008).

A body of evidence suggests that older mice and rats have reduced interest in various hedonic stimuli, such as palatable food and drinking solutions, alcohol and a regular diet (Spear and Varlinskaya, 2010; Blanton et al., 1998). In the chronic stress model, older rats showed enhanced susceptibility to anhedonic-like changes in a sucrose test 
and a delayed response to the antidepressant effects of citalopram (Herrera-Pérez et al., 2008, 2010). Aging in rodents resulted in diminished place preference conditioned to a food (Rubinow et al., 2009), nicotine, cocaine, morphine and alcohol (Vastola et al., 2002; Campbell and Wood, 2000). It is also associated with lower novelty exploration (Vastola et al., 2002; Campbell and Wood, 2000) and decreased scores of grooming (Scimonelli et al., 1999; Shoji and Mizoguchi, 2011), which are considered to reflect a reduced self-rewarding activity (Pothion et al., 2004; Dubreucq et al., 2010; Gómez-Lázaro et al., 2011; Park et al., 2011). Together, these findings from animal studies parallel clinical features of elderly depression, which are predominantly related to hedonic deficits (Gallo et al., 1994, 1997).

Though affective disturbances are less typical of sentient depression (Lawton et al., 1996), translational studies report elevated scores of behavioral despair in elderly animal cohorts (Frye and Walf, 2009; Moretti et al., 2011). In the paradigm of operant extinction of escape from water, the removal of the platform in the Morris water maze induces higher scores of floating behavior in 24-month-old Wistar rats than in younger animals (Schulz et al., 2007). Similarly, the enhancement of floating behavior in the forced swim test evoked in BALB/C mice by lipopolysaccharide is two-fold higher in 20- to 24-monthold than in 3-month-old animals (Godbout et al., 2008).

The present study examined the parameters of reward sensitivity and behavioral despair in 18-month-old versus 3-month-old male mice of the $\mathrm{C} 57 \mathrm{BL} / 6 \mathrm{~N}$ strain, which is commonly used in translational research on depression. The available literature suggests that aged rats and mice of various strains with behavioral signs of hedonic and affective deficits also show psychomotor disturbances when tested at certain ages (Schulz et al., 2007; Soffié et al., 1992; Bowman et al., 2006), but not at others (Frye and Walf, 2009; Moretti et al., 2011; David et al., 2001; Gould and Feiro, 2005). The efficacy of different classes of antidepressants also depends on the age of the experimental animals (Bourin et al., 1998). The use of animals within the age range at which depressive-like features emerge while general age-related behavioral changes are still minimal, and, thus, can be ignored, is important for minimizing confounding factors in rodent models of elderly depression. Our preliminary experiments demonstrated that depressive-like behaviors are accompanied by general locomotor and consumatory abnormalities in 25- but not 18-monthold C57BL6/N mice (Bolkunov et al., 2009). To determine whether 18-month-old animals display depressive features without generalized psychomotor deficits, they were compared to 3-month-old mice in an extended test battery for commonly used measures of anhedonia, behavioral despair, anxiety-like behavior, grooming, exploration and locomotion (Pothion et al., 2004; Surget et al., 2008; Strekalova, 2008; Strekalova and Steinbusch, 2009).

Clinical studies show that the symptoms of hedonic deficit typically outweigh affective disturbances in patients with elderly depression. The self-reported "lack in positive affect" is consistent in elderly patients with major depression, while the emergence of "negative affect" is variable (Lawton et al., 1996). Older primarily depressed patients were less likely to endorse crying spells, sadness, feeling fearful, being bothered, or feeling like a failure, and were less likely to have co-morbid anxiety, but tended to experience poor appetite and loss of interest in sex (Hybels et al., 2011). A study of more than 6500 participants showed that persons aged 65 years and older were less likely to acknowledge dysphoria than anhedonia (Gallo et al., 1994). A 13-year follow-up study of more than 1500 depressed patients aged 50 years and older revealed the significant prevalence of a form of disorder whose core criteria included hedonic deficit but not sadness or dysphoria (Gallo et al., 1997).

We therefore addressed whether both anhedonic and affective features change in C57BL6 mice of 18-month-old age. Anhedonic behavior defined by decreased sucrose intake and preference on one hand, and signs of behavioral despair in the forced swim and modified tail suspension tests on the other, have been extensively validated as parameters of reward sensitivity and affective traits in mice and rats (Porsolt and Papp, 1998; Willner, 2005; Strekalova et al., 2011; Yacoubi et al., 2011). In sum, using these paradigms and additional tests, the present study examined whether, in comparison with 3-month-old mice of the C57BL6N strain, 18-month-old mice (1) exhibit changes indicative of the depressive state in the sucrose test, novelty exploration, splash test, forced swim and modified tail suspension paradigms, (2) show the prevalence of one type of deficit, hedonic- or affective-like, over the other, whether (3) older animals have disturbances in daily liquid intake, anxiety-like behavior and locomotion that are non-specific to depressive-like traits and (4) parameters of depressive-like behavior in aged animals are sensitive to antidepressant treatment.

In addition to a classical antidepressant imipramine, we also assessed the effects of dimebon, an investigational drug against Alzheimer's and Huntington's diseases with proposed proneurogenic neuroprotective properties. Dimebon, a tetrahydro-g-carboline with anti-histamine effects, was reported to block the apoptosis of cortical neurons (Bachurin et al., 2001), protect the mitochondrial membrane potential (Bachurin et al., 2003; Pieper et al., 2010), promote neurite outgrowth in cultured hippocampal and cortical neurons (Protter et al., 2009; Bernales et al., 2009), dose-dependently increase neurogenesis in the rat dentate gyrus (Pieper et al., 2010), act in vitro as a low-affinity NMDA receptor blocker via the NR2B subunit (Perlovich et al., 2009) and enhance memory properties in middle-aged mice (Vignisse et al., 2011). The role of these factors in the neurobiology of depression was generally documented (Skolnick et al., 2009; Pittenger and Duman, 2008; Marcocci et al., 2002), however, it remains to be studied whether dimebon may exert any systemic effects via these mechanisms (Bachurin, 2003).

\section{Material and methods}

\subsection{Animals, housing and general experimental conditions}

Three- and 18-month-old C57BL/6N mice were used in this study. Following purchase from the supplier, mice were housed in individual cages for at least 2 weeks before testing. Standard laboratory conditions $\left(22 \pm 1{ }^{\circ} \mathrm{C}, 55 \%\right.$ humidity, food and water ad libitum) and a reverse $12 \mathrm{~h}: 12 \mathrm{~h}$ light-dark cycle (lights on: 21:00 h) were applied throughout the study. Mice were tested during the dark period of the light cycle. All experiments were carried out in accordance with the European Committees Council Directives.

\subsection{Study design}

2.2.1. Experiment 1: study of behavioral measures of hedonic sensitivity in old versus young mice

Experiment 1 examined the consumption of palatable solutions by old versus young mice using two paradigms of the sucrose intake test. A decrease in sucrose intake and preference over water is generally taken as a putative sign of anhedonia in rodents (Strekalova and Steinbusch, 2010; Porsolt and Papp, 1998; Willner, 2005). This experiment aimed to investigate the effects of aging on behavioral measures of hedonic status in mice. Three- and 18-month-old mice were tested in a two-bottle free-drinking paradigm with a $1 \%$ sucrose solution (see Section 2.3.1). Experimental groups comprised 15 mice, body weight was compared to young and old mice. To estimate liquid intake during aging, 24-h water consumption was compared between two groups in a separate test; each group comprised 10 animals (see Section 2.3.2).

The consumption of a $5 \%$ sucrose solution requiring a high level of drinking effort from a bottle with a narrow nipple was then assessed in young versus old animals in a one-bottle paradigm (see Section 2.3.3, five animals in each group). In order to assess the ability of sweet taste of older mice, the intake of a $5 \%$ sucrose solution from regular bottles was evaluated one week earlier in two groups of mice in a free-access one-bottle paradigm (see Section 2.3.3). In order to compare the physical ability of young and old mice to drink 
in a situation that required high levels of effort, their water intake was estimated on the fourth day thereafter (between the two tests on sucrose intake; see Section 2.3.3).

\subsubsection{Experiment 2: study of parameters of behavioral despair during aging}

Experiment 2 scored parameters of behavioral despair in younger and older mice tested for hedonic sensitivity in the modified forced swim (Section 2.3.4) and the modified tail suspension (Section 2.3.5) tests; behavior was videotaped. First, CleverSys software (CleverSys, Reston, VA, USA) was applied for automated scoring of the floating and immobility behaviors, as well as the duration of swimming in the forced swim test and of locomotor activity in the modified tail suspension test. The duration of climbing behavior and the number of diving events were scored supplementary in the forced swim test. Automated scoring of behaviors was analyzed per 1minute interval and per entire scoring period; for technical reasons, only the first 5 min were scored (see Sections 2.3.4 and 2.3.5).

Second, the latencies of the first episodes of floating and immobility behavior, as well as the duration of these behaviors, were scored manually off-line. Both tests were validated pharmacologically for sensitivity to antidepressant treatment. In a separate validation study, 10 mice at the age of 3 months were treated either with a single acute i.p. injection of imipramine at the dose $30 \mathrm{mg} / \mathrm{kg} 30 \mathrm{~min}$ prior to the first exposure to a forced swim or modified tail suspension tests, or with vehicle (see Section 2.4) Behavior was scored as described below (see Sections 2.3.4 and 2.3.5). This scheme of pharmacological validation was adapted from originally published studies with tricyclics in these tests (Steru et al., 1985, 1987; Porsolt et al., 1987). To enable a data comparison from two experiments, data obtained on older mice and on pharmacologically treated mice were normalized to the means of values of younger and vehicle-treated 3-month-old mice, respectively.

\subsubsection{Experiment 3: study of parameters of locomotion, exploration, grooming and anxiety}

Experiment 3 examined potential aging-related changes in the parameters of anxiety and locomotion that could interfere with the evaluation of depressive-like behaviors. Grooming behavior and three parameters of novelty exploration were scored in groups of both ages in the splash test, the True scan open-field and novel cage tests to further assess the hedonic/motivational state of old mice. Three- and 18-month-old mice were analyzed in the True scan open-field, novel cage, 0 -maze and dark/light box $(\mathrm{n}=12$ and $\mathrm{n}=11$, respectively; see Sections 2.3.6-2.3.10) and in the splash test $(n=15$ in each group; see Section 2.3.8).

\subsubsection{Experiment 4: effects of imipramine and dimebon on hedonic and affective behaviors}

In Experiment 4, we investigated whether the classical antidepressant imipramine and potentially neuroprotective proneurogenic drug dimebon administered to 18 -month-old mice for 4 weeks at the doses $7 \mathrm{mg} / \mathrm{kg} /$ day and $1 \mathrm{mg} / \mathrm{kg} /$ day, respectively, affected the parameters of the sucrose preference test, the latter indicating the state of anhedonia. These animals were tested for floating and immobility in visually scored modified forced swim and modified tail suspension tests (see Sections 2.3.4 and 2.3.5). The dose of imipramine was based on previous studies with CD1 mice, in which its chronic administration at $7 \mathrm{mg} / \mathrm{kg} / \mathrm{day}$ effectively reduced the stress-induced decrease in sucrose intake and preference, floating behavior and alteration of hippocampal gene expression typical of the subgroup of mice susceptible to anhedonia (van Miegem et al., 2009). The dosage of dimebon was determined according to its efficacy in clinic (Doody et al., 2008), as well as in improving learning in the Morris water maze paradigm in aged Wistar rats treated with $1 \mathrm{mg} / \mathrm{kg} / \mathrm{day}$ of this compound for 3 weeks (Lermontova et al., 2000) and in C57BL6N mice in a step-down avoidance and conditioned fear extinction tests
(Vignisse et al., submitted for publication). Drugs were delivered in the drinking water (see Section 2.4).

Body weight and baseline behaviors, including the initial preference for a $1 \%$ sucrose solution (see Section 2.3.1), were evaluated in order to form experimental groups which are initially balanced in these parameters, as described elsewhere (Strekalova et al., 2006). Each group comprised 5 to 10 mice, the number of animals being indicated in the legend of Fig. 5.

\subsection{Behavioral tests}

\subsubsection{Two-bottle sucrose preference test}

Mice of both ages were simultaneously given a free choice between two bottles, one with $1 \%$ sucrose solution and another with tap water, for $8 \mathrm{~h}$, between 09.00 and 17.00 . The beginning of the test started with the onset of the dark (active) phase of the animals' cycle. No previous food or water deprivation was applied before the test. To minimize the spillage of liquids during the sucrose test, specially manufactured bottles with a glass tip (length of $6 \mathrm{~cm}$, internal diameter $2 \mathrm{~mm}$; they were inserted in flavorless rubber bottlestoppers) were used. Special attention was devoted to sugar storage to avoid its contact with flavors and plastic, and to washing of bottles, where minimal amounts of detergent were used. Bottles were filled in advance (during the preceding evening) and were kept upside down for at least $12 \mathrm{~h}$ prior to testing. In order to balance the air temperature between the room and the drinking bottles, they were kept in the same room where the testing took place. This measure prevents the physical effect of liquid leakage resulting from growing temperature of air and pressure inside the bottles, when they are filled with liquids which are cooler than the room air. To prevent the possible effects of a side-preference in drinking behavior, the position of the bottles in the cage was switched after $4 \mathrm{~h}$ during the test. The test was carried out before weekly cage change. With this method proposed, the error of measurement of liquid intake does not exceed $0.1 \mathrm{ml}$.

The intake of water and $1 \%$-sucrose solution and total intake was estimated by weighing the bottles before and after access to liquids. The preference for sucrose was calculated as the percentage of the sucrose solution consumed out of the total amount of liquid drunk:

\section{Sucrose Preference}

$=[\mathbf{V}($ Sucrose solution $) / \mathbf{V}($ Sucrose solution $)+\mathbf{V}($ Water $)] \times 100 \%$

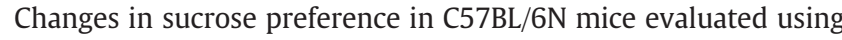
the above-described protocol correlated with molecular, electrophysiological, behavioral and biochemical alterations characteristic of a depressive-like state (Strekalova et al., 2011). Further details of methodological conditions were applied as described elsewhere (Strekalova and Steinbusch, 2010).

\subsubsection{Daily water intake in one-bottle drinking test}

A 24-h water drinking test was carried out simultaneously in both groups of mice in a one-bottle paradigm starting at 17.00. Specialized drinking bottles such as those employed in the above-described sucrose test (see Section 2.3.1) were used. A test procedure was carried out as described elsewhere (Strekalova and Steinbusch, 2010). The same precautions concerning possible liquid spillage as in the sucrose test were applied: bottles were filled with tap water in advance and kept in the experimental room $12 \mathrm{~h}$ prior to the test, being held upside down during this time. The intake of water was estimated by weighing the bottles before and after access to liquids. The test was carried out two days before weekly cage change.

\subsubsection{Sucrose and water intake in high-effort and free-access one-bottle drinking tests}

In a high-effort one-bottle drinking paradigm, the amount of concentrated sucrose solution ingested is taken as a measure of the 
animal's motivation to receive a pleasurable stimulus. In this test, mice of both ages were simultaneously given access to a $5 \%$ sucrose solution or tap water for $8 \mathrm{~h}$ (between 09.00 and $17.00 \mathrm{~h}$ ), the ingestion of which required a high level of effort due to the narrow bottle tip, the internal diameter of which was $1.0 \mathrm{~mm}$ instead of $2.0 \mathrm{~mm}$ as in a regular bottle. Preliminary studies showed that this modification resulted in a reduction in the 24 -h water intake of at least $50 \%$ of normal amounts. The consumption of sucrose solutions from these bottles was high, suggesting that it can be used to measure animals' effort/motivation to receive a reward. The intake of a $5 \%$ sucrose solution was also evaluated in a single-bottle free-drinking paradigm using regular bottles for $8 \mathrm{~h}$. The intake of water and sucrose solution was estimated by weighing the bottles before and after access to liquids.

\subsubsection{Forced swim test}

The test protocol was adapted from a previously described procedure with minor modifications (Porsolt and Papp, 1998; Strekalova et al., 2005; Ducottet et al., 2004). Mice were subjected to two 6-min swimming sessions spaced $24 \mathrm{~h}$ apart in a transparent cylinder $(\varnothing 17 \mathrm{~cm})$ filled with water $\left(+23^{\circ} \mathrm{C}\right.$, water height $13 \mathrm{~cm}$, height of cylinder $20 \mathrm{~cm}$, illumination intensity $25 \mathrm{~lx}$ ). The slightly deeper water used in our protocol was shown to increase test sensitivity (Cryan et al., 2005a). First, by means of the data from the automated scoring system, the duration of floating, swimming and climbing behavior and the number of diving events during the first five minutes and during one-minute intervals within the scoring period were analyzed (see Section 2.2.2).

Second, scoring by visual observation was carried out by two independent observers who were blinded with regard to the animals' age and treatment (where applicable). The latency of the first episode of floating and the duration of floating behavior were recorded during 2-min intervals within the 6-min swimming session and for a total period on day 1 and day 2 of the test (see Section 2.2.2). Floating behavior was defined in accordance with the commonly accepted criteria of this behavior. Namely, a mouse was considered to be floating when only slight movements of its limbs and tail could be detected, without signs of searching activity; passive movements of the body while drifting on the surface of the water have no direction (Strekalova et al., 2005; Ducottet et al., 2004; Cryan et al., 2005a; Mineur et al., 2006). Latency of floating was determined as the time between the placement of a mouse in a water tank and the first bout of floating behavior.

\subsubsection{Modified tail suspension test}

The protocol used in this study was adapted from a previously proposed procedure (Mineur et al., 2006). Mice were subjected to the modified tail suspension by being hung by their tails with adhesive tape to a rod $50 \mathrm{~cm}$ above the floor for $6 \mathrm{~min}$. Two animals were tested simultaneously in a dark room where only the area of the modified tail suspension construction was illuminated by a spotlight from the ceiling; the lighting intensity on the height of the mouse position was $25 \mathrm{~lx}$. The trials were recorded by a video camera positioned directly in front of the mice while the experimenter observed the session from a distance in a dark area of the experimental room. This procedure was carried out twice with a 24-h interval between tests, similarly to previously reported protocols (Vaugeois et al., 1997; Gavioli et al., 2004). First, during the additional automated scoring, the duration of immobility and activity was scored during the first five minutes and during oneminute intervals within the scoring period (see Section 2.2.2).

Second, in line with generally accepted protocols, the latency of the first episode of immobility and the total duration of this behavior were scored manually as described elsewhere (Mineur et al., 2006; Vaugeois et al., 1997), and the scoring was performed during 2-min sub-intervals within a 6-min session and summarized for the entire period on day 1 and day 2 (see Section 2.2.2). Therefore, videotapes were scored by two independent observers who were blinded with regard to the animals' age and treatment by manual analysis, in accordance with the commonly accepted criteria of immobility (Cryan et al., 2005b; Ibarguen-Vargas et al., 2009). The immobility behavior was defined as the absence of any movements of the animals' head and body. The latency of immobility was determined as the time between the onset of the test and the first bout of immobility. The means of the values obtained by the two observers were analyzed.

\subsubsection{TruScan open-field test}

Mice were placed into True Scan activity boxes $(26 \mathrm{~cm} \times 26 \mathrm{~cm} \times$ $39 \mathrm{~cm}$; Coulbourn Instruments, Allentown, PA, USA) for $10 \mathrm{~min}$. Boxes were evenly illuminated with white light, with an illumination intensity of $25 \mathrm{~lx}$. Horizontal movements (speed), resting time, the duration of exploration during rearing and of nose poke behavior, were scored automatically by red beam cells using TruScan software (Coulbourn), as described elsewhere (Strekalova et al., 2004). Animals were placed in the experimental room at least $1 \mathrm{~h}$ prior to the experiment. The testing was carried out in the morning between 09.00 and 12.00 . Mice of both ages were tested simultaneously; two animals were used in each run. Boxes were cleaned with water between the runs.

\subsubsection{Novel cage test}

The novel cage test was performed to assess exploration of a new environment, as described elsewhere (Strekalova et al., 2004). Mice were introduced into a standard plastic cage the size of their home cage filled with small amounts of fresh sawdust. The number of exploratory rearings was counted under red light during a 5 -min period. The testing was carried out in a dark quiet room in morning hours. Behavior was videotaped and analyzed by trained observers blind to the animals' age.

\subsubsection{Splash test}

This test was performed as described elsewhere (Pothion et al., 2004; Surget et al., 2008). A $10 \%$ sucrose solution was spread on the dorsal surface of a mouse coat, which because of its high viscosity induces lasting grooming behavior in mice. As animals were singlehoused, no prior isolation needed to be applied on this occasion. The parameters generally accepted for splash tests, i.e. latency of the first episode of grooming, number of grooming episodes and duration of grooming behavior, were measured in 3-and 18-month-old mice by trained observers.

\subsubsection{Elevated 0 -maze}

The apparatus (Technosmart, Rome, Italy), which consisted of a circular path (runway width $5.5 \mathrm{~cm}$, diameter $46 \mathrm{~cm}$ ), was placed $50 \mathrm{~cm}$ above the floor. Two opposing arms were protected by walls (height $10 \mathrm{~cm}$ ), and the illumination strength was $25 \mathrm{~lx}$. The apparatus was placed on a dark surface in order to reduce reflection and maintain control over lighting conditions during testing. Anxiety-like behavior was assessed using previously validated parameters (Strekalova et al., 2005; Vignisse et al., 2011). Mice were placed in one of the closedarm compartments of the apparatus. The latency of the first exit to the anxiety-related open compartments of the maze, the total duration of time spent therein and the number of exits to the open arms were scored during a 5-min observation period.

\subsubsection{Dark/light box}

The dark/light box (Technosmart, Rome, Italy) consisted of two plexiglass compartments, one black/dark $(15 \mathrm{~cm} \times 20 \mathrm{~cm} \times 25 \mathrm{~cm})$ and one lit $(30 \mathrm{~cm} \times 20 \mathrm{~cm} \times 25 \mathrm{~cm}$ ), connected by a tunnel. Anxietylike behavior was assessed by earlier validated measures (Strekalova et al., 2005; Vignisse et al., 2011). Mice were placed into the dark compartment, from where they could visit the lit box, illuminated by light of $25 \mathrm{~lx}$ intensity. The latency of the first exit to the light compartment, the total duration of time spent in the lit box and the number of visits to this anxiety-related compartment were scored by visual observation over $5 \mathrm{~min}$. 


\subsection{Drugs and drug administration}

For a validation study with tests for affective behavior, imipramine (Sigma Aldrich, St. Louis, MO, USA) was dissolved in water for injection and administrated to mice via a single i.p. injection at the dose of $30 \mathrm{mg} / \mathrm{kg} 30 \mathrm{~min}$ prior to the first exposure to forced swim or modified tail suspension tests. The same treatment scheme was applied to administer a vehicle; the volume of imipramine and vehicle injections was $0.01 \mathrm{ml} / \mathrm{kg}$.

In the study with 3- and 18-month-old mice, imipramine (from the same source as in above-mentioned study) and dimebon (obtained from the Institute of Physiologically Active Compounds, Chernogolovka, Russia) were administered for 4 weeks via drinking water at the doses of 7 and $1 \mathrm{mg} / \mathrm{kg} / \mathrm{day}$, respectively. Both drugs were dissolved in tap water; the solutions were changed on average every 3 and 5 days, respectively. Due to the light sensitivity of imipramine, its solution was renewed more frequently, and the bottles were covered with aluminum. Calculation of the drug concentrations in drinking water was based on the means of a 3-day evaluation of daily water consumption in both groups of mice, which were in fact similar (Fig. 1D), and on the desirable treatment dosage. This method of dosing in C57BL6N mice was previously validated in chronic stress experiments using citalopram (Strekalova et al., 2006).

\subsection{Statistical analysis}

Data were analyzed using the statistical software package Prism 5 (Chicago, IL, USA) unless otherwise specified. Despite normal distribution of the data from drinking tests, two-group comparisons were analyzed with non-parametric Mann-Whitney $U$ test and multiple group comparisons were treated by non-parametric Kruskal-Wallis test, since few values were close to the error of measurement and they were considered as arbitrarily taken. Because of a limited accuracy of manual scoring for the forced swim and modified tail suspension behaviors, these data were also analyzed using this method. To compare variances, F test was applied. Body weight, other visually scored behaviors and the automated scores of the forced swim and modified tail suspension were analyzed using an unpaired $t$-test; the latter analysis was carried out using CleverSys software (CleverSys, Reston, VA, USA). The level of confidence was set at $95 \%(p<0.05)$.

\section{Results}

3.1. Experiment 1: study of behavioral measures of hedonic sensitivity in old versus young mice

\subsubsection{Two-bottle sucrose preference test}

In Experiment 1, 18-month-old animals showed significantly lower preference to $1 \%$ sucrose solution over water $(p=0.0005, U=33.0$; Fig. 1A), lower sucrose intake ( $p=0.0016, U=41.0$; Fig. $1 B$ ) and a tendency to drink more water ( $p=0.0704, \mathrm{U}=76.5$; Fig. $1 \mathrm{C}$ ) compared to 3-month-old mice. The 24 -h water intake in a one-bottle paradigm did not differ between groups ( $p=0.39, \mathrm{U}=41.5$; Fig. 1D), demonstrating their similar metabolic need for water. Aged mice had a significantly higher body weight $(\mathrm{p}=0.016, \mathrm{t}=12.85, \mathrm{df}=28$; Fig. $1 \mathrm{E})$ than the young mice, suggesting that the above-described differences in sucrose intake and preference are unrelated to differences in body mass and caloric requirement. The reproducibility of decreases in sucrose intake and preference found in 18-month-old mice was demonstrated in independent experiments; there were no seasonal effects observed in these studies (data not shown).

\subsubsection{Sucrose and water intake in high-effort one-bottle drinking test}

In the high-effort one-bottle drinking test, the amount of $5 \%$ sucrose liquid consumed was taken as a measure of the animal's motivation to receive a pleasurable stimulus. This parameter was significantly lower in 18-month-old mice than in 3-month-old mice $(p=0.01, U=3.0$; Fig. 1G). While young mice showed a significant increase in $5 \%$ sucrose intake in comparison to intake of water, which was separately evaluated in a high-effort drinking paradigm $(p=0.02, U=21.0$; Fig. $1 G)$, older animals showed no such difference $(p>0.05, U=6.0)$. In this experiment, the two groups of mice showed similar levels of water intake ( $p>0.05, U=15.5$ ) suggesting comparable ability to drink from bottles with narrow tips for 3 - and 18-month-old animals. The intake of the 5\% sucrose solution in free-drinking conditions showed no difference between groups, indirectly demonstrating the undisturbed ability of the older group to taste the sucrose solution at the concentration employed ( $>0.05, U=15.0$; Fig. $1 G$ ).

\subsection{Experiment 2: study of parameters of behavioral despair during aging}

\subsubsection{Forced swim test}

Automated analysis revealed no differences between young and aged groups in the total duration of floating behavior $(p=0.31$, $\mathrm{df}=26$; $t$-test $)$ and swimming behavior $(\mathrm{p}=0.26, \mathrm{df}=26$; data not shown). Experimental groups showed similar mean values for these variables measured during one-minute intervals ( $p>0.05$; Fig. $2 \mathrm{~A}$ ). The duration of climbing and the number of diving events did not differ between 3- and 18-month-old animals $(\mathrm{p}=0.93, \mathrm{df}=28$ and $\mathrm{p}=0.11, \mathrm{df}=26$, respectively; Fig. 2B,C). Aged animals demonstrated significantly higher variability in the latter behavior than young mice $(\mathrm{p}<0.0001$, F test $)$.

Manual analysis of the forced swim test showed that 3- and 18-month-old mice had similar values of latencies of floating on day 1 (3-month-old mice: $92.9 \pm 9.3 \mathrm{~s}$, 18-month-old mice: $105.9 \pm$ $6.6 \mathrm{~s} ; \mathrm{p}=0.06, \mathrm{U}=74.5)$ and day 2 (3-month-old mice: $9.1 \pm 2.3 \mathrm{~s}$, 18-month-old mice: $11.3 \pm 3.3 \mathrm{~s} ; \mathrm{p}=0.39, \mathrm{U}=105.0$; Fig. $3 \mathrm{~A}, \mathrm{C})$. The imipramine-treated group had longer latency of floating than vehicletreated mice (day $1: p=0.005, U=29.0$, day $2: p=0.0007, U=17.5$ ). Multiple comparison revealed significant differences in the normalized values of this parameter between three groups of 3-month-old mice (day $1: \mathrm{p}=0.01$, Kruskal-Wallis test $=8.49$; day $2: \mathrm{p}=0.004$, KruskalWallis test $=10.74)$. Total duration of floating was similar in the age comparison experiment on day $1(p=0.3, U=87.5$, mean values of floating in young and old mice: $154.2 \pm 13.7 \mathrm{~s}$ and $143.9 \pm 12.0 \mathrm{~s}$, respectively) and day $2(\mathrm{p}=0.09, \mathrm{U}=71.0$, mean values of floating in young and old mice: $250.7 \pm 10.6 \mathrm{~s}$ and $234.1 \pm 7.6 \mathrm{~s}$, respectively; Fig. 3B,D). This parameter was significantly lower in imipramine-treated versus vehicle-treated mice on days 1 and $2(p=0.004, U=15.0$ and $p=0.02$, $\mathrm{U}=23.0$, respectively). Multiple comparison revealed significant differences in normalized values of total duration of floating between three groups of 3-month-old mice (day 1: $\mathrm{p}=0.04$, Kruskal-Wallis test $=6.02$; day $2: \mathrm{p}=0.02$, Kruskal-Wallis test $=8.14$ ). A comparison of scores of floating measured over 1- or 2-min intervals did not reveal any differences between the groups of two ages (data not shown).

\subsubsection{Modified tail suspension test}

Analysis with the CleverSys software found no differences between 3- and 18-month-old mice in the total duration of immobility behavior $(p=0.18, d f=23)$ and locomotor activity $(p=0.12$, $\mathrm{df}=23$; data not shown). Aged and young animals showed no significant differences in the duration of these behaviors scored during one-minute intervals ( $p>0.05$; Fig. $2 \mathrm{C}$ ).

Manual analysis of the modified tail suspension test indicated that 3and 18-month-old mice had no difference in latencies of immobility on day 1 (3-month-old mice: $36.4 \pm 6.5 \mathrm{~s}, 18$-month-old mice: $43.3 \pm 7.7 \mathrm{~s}$; $\mathrm{p}=0.35, \mathrm{U}=95.5$; Fig. $3 \mathrm{E}$ ) and day 2 (3-month-old mice: $33.3 \pm 6.3 \mathrm{~s}$, 18-month-old mice: $37.1 \pm 5.8 \mathrm{~s} ; \mathrm{p}=0.32, \mathrm{U}=101.0$; Fig. 3G). Animals injected with imipramine demonstrated significant increase of latency of immobility as compared with vehicle-treated mice on day $1(p=0.01, U=20.0)$ and day $2(p=0.03, U=30.5)$. Multiple 


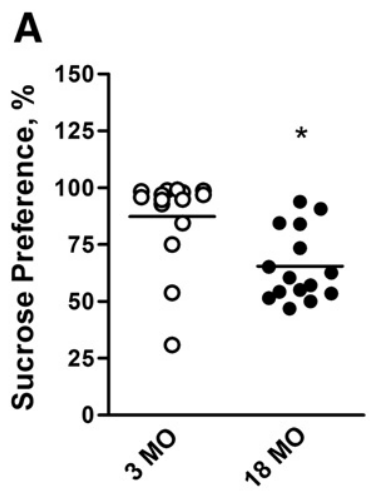

\section{SUCROSE TEST}

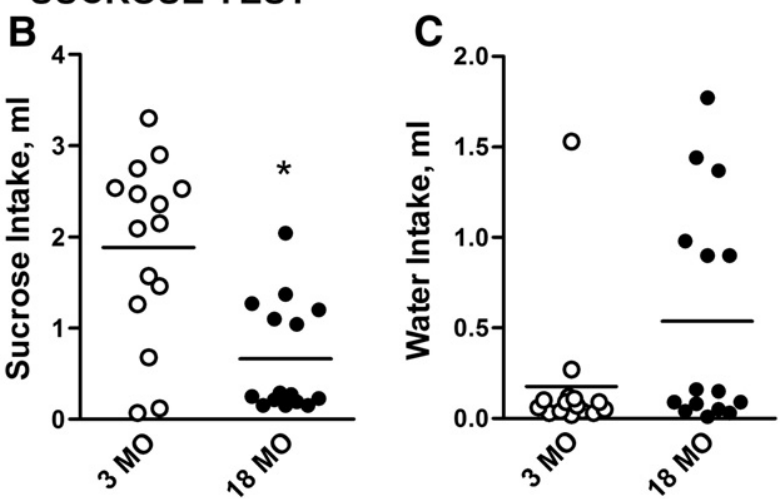

DAILY WATER INTAKE

BODY WEIGHT
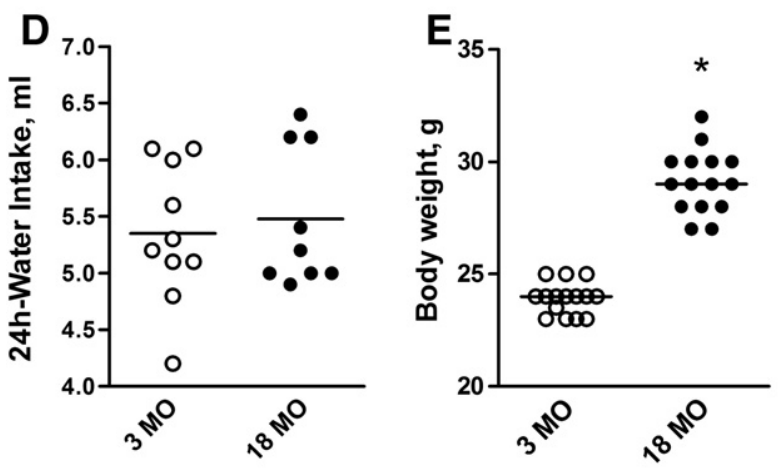

$\mathbf{F}$

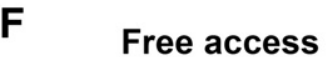

High drinking effort

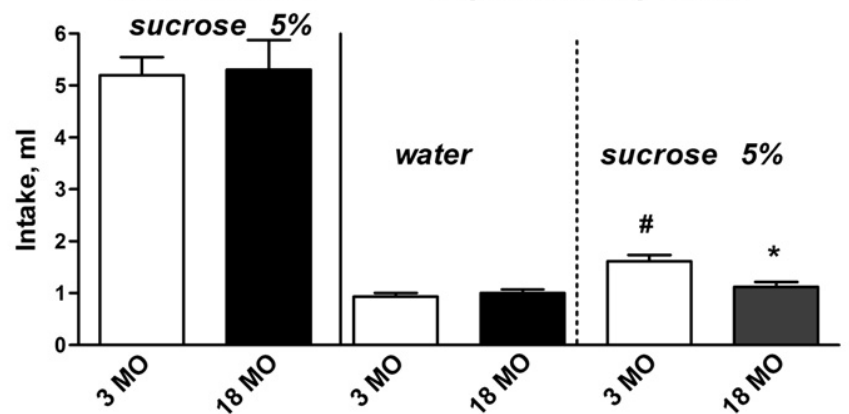

Fig. 1. Decreased sucrose intake and preference in 18-versus 3-month-old mice. In a free-access paradigm, in comparison with 3-month-old mice, 18-month-old mice exhibited significantly lower sucrose preference (A), decreased sucrose intake (B) and a tendency to increased water intake (C) $\left({ }^{*} \mathrm{p}<0.05\right.$, 3-vs. 18-month-old mice; Mann-Whitney $U$-test). (D) Twenty-four-hour water consumption was similar in both groups ( $p>0.05$, 3- vs. 18-month-old mice; Mann-Whitney $U$-test). (E) Body weight was significantly higher in aged mice $\left({ }^{*} p<0.05,3\right.$ - vs. 18 -month-old mice; unpaired $t$-test). (F) In a high-effort drinking test, intake of $5 \%$ sucrose solution was significantly lower in 18 -month-old mice than in 3 -month-old mice $\left({ }^{*} \mathrm{p}<0.05\right.$, 3- vs. 18-month-old mice; Mann-Whitney $U$-test). The young mice showed significantly higher consumption of $5 \%$ sucrose solution than intake of water (\#p $<0.05$, intake of water vs. $5 \%$ sucrose solution, 3-month-old mice, Mann-Whitney $U$-test); older animals showed no such difference ( $>>0.05$, intake of water vs. $5 \%$ sucrose solution, 18 -monthold mice Mann-Whitney $U$-test). There was no significant difference in water intake between the groups ( $p>0.05,3$ - vs. 18-month-old mice, Mann-Whitney $U$-test). The intake of $5 \%$ sucrose solution in free-drinking conditions did not differ between groups. Bars represent the means of the groups. Each column represents the mean \pm SEM. $3 \mathrm{MO} 3$-month-old mice (A-C: $n=15 ; D-E: ~ n=10 ; F: n=5) ; 18$ MO: 18-month-old mice (A-C: $n=15 ; D-E: ~ n=10 ; F: n=5)$.

comparison revealed significant differences in normalized values of latency of immobility between three groups of 3-month-old mice (day $1: \mathrm{p}=0.02$, Kruskal-Wallis test $=7.11$; day $2: \mathrm{p}=0.02$, Kruskal-Wallis test $=7.96)$. 3- and 18-month-old mice did not differ in duration of immobility on day 1 (3-month-old mice: $160.1 \pm 10.4 \mathrm{~s}$, 18 -month-old mice: $150.0 \pm 9.6 \mathrm{~s} ; \mathrm{p}=0.54, \mathrm{U}=84.0$; Fig. $3 \mathrm{~F}$ ) and day 2 (3-monthold mice: $242.1 \pm 10.7 \mathrm{~s}$, 18 -month-old mice: $227.4 \pm 8.8 \mathrm{~s} ; \mathrm{p}=0.16$, $\mathrm{U}=78.0$; Fig. 3H). Imipramine-treated mice showed decreases in duration of immobility on days 1 and $2(p=0.04, U=27.0$ and $p=0.002$, $U=14.0$ ). Similarly to the outcome of the forced swim test, potentially more sensitive evaluation of both measured parameters at shorter intervals failed to reveal any differences between the groups (data not shown).
3.3. Experiment 3: study of locomotor, exploration, grooming and anxiety-like behaviors

\subsubsection{True Scan open-field and novel cage tests}

In the True Scan open-field test, the mean speed of movement and resting time were similar in 3- and 18-month-old mice $(p=0.80$ $\mathrm{df}=21$ and $\mathrm{p}=0.54, \mathrm{df}=21.0$; respectively; Fig. $4 \mathrm{~A}, \mathrm{~B}$ ). In comparison to young mice, older mice displayed a significantly reduced duration of nose poke behavior and rearing activity in the open-field test $(p=0.007, d f=19$ and $p=0.02, d f=18$, respectively; Fig. $4 C, D)$ and fewer rearings in the novel cage test $(\mathrm{p}=0.04, \mathrm{df}=71$; Fig. $4 \mathrm{E})$. These data demonstrate the lack of locomotor disturbances under the lighting conditions used in the behavioral studies of 18-month- 

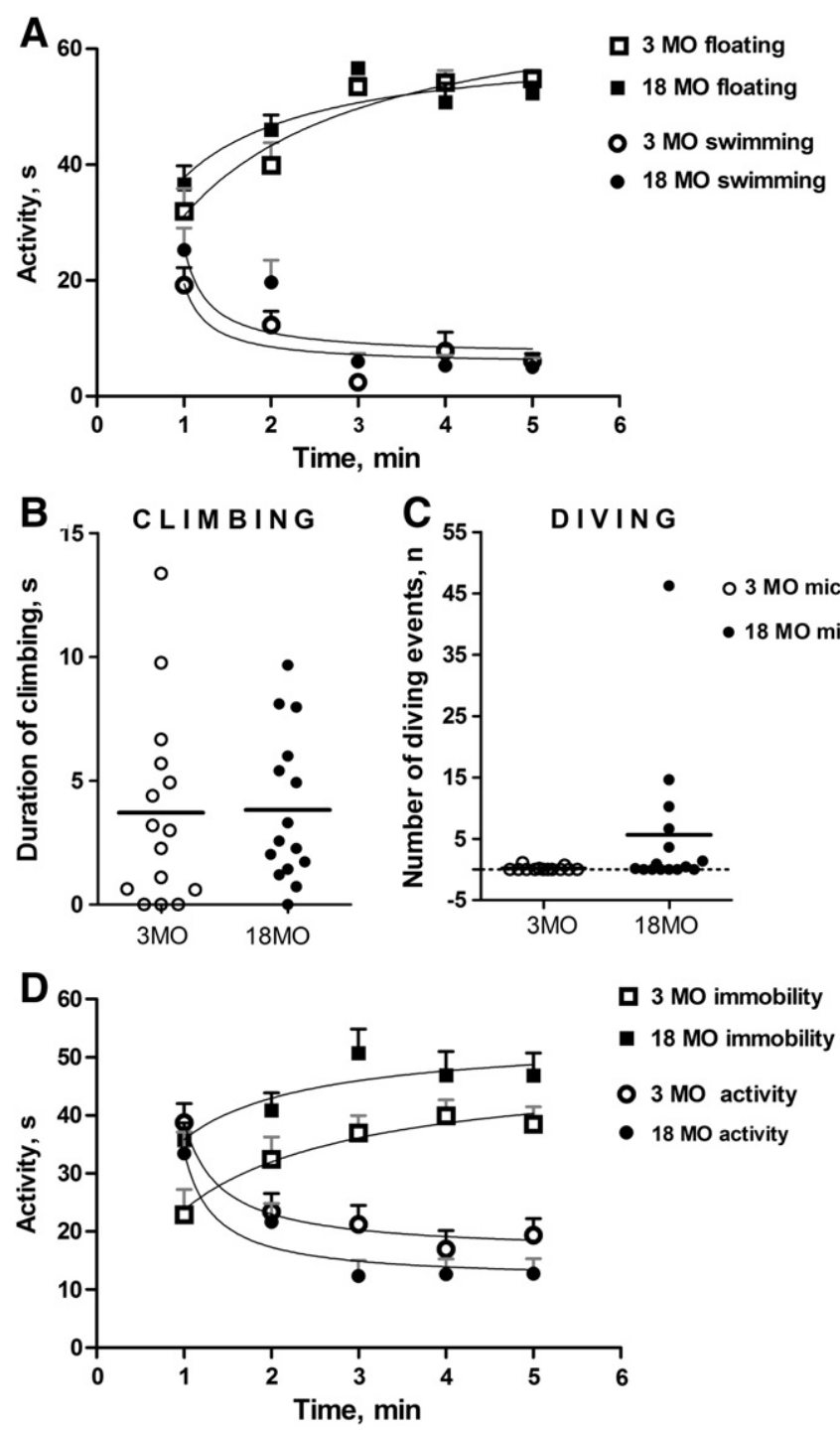

Fig. 2. Automated analysis of the forced swim and modified tail suspension tests in young and old mice. (A) In the forced swim test, 3- and 18-month-old mice showed a similar mean duration of floating and swimming behaviors scored using the CleverSys software during one-minute intervals ( $\mathrm{p}>0.05$; unpaired $t$-test). (B) Young and aged mice showed a similar duration of climbing and (C) number of diving events ( $>>0.05$; unpaired $t$-test). (D) In the modified tail suspension test, groups of aged and young animals showed no differences in the total duration of immobility behavior and activity. Bars represent the means. 3 MO: 3-month-old mice ( $\mathrm{n}=15)$; $18 \mathrm{MO}$ : 18-month-old mice $(n=15)$.

old mice and their lowered exploration of novelty, compared with 3-month-old animals.

\subsubsection{Grooming behavior in splash test}

Compared with 3-month-old animals, 18-month-old mice exhibited significantly longer latency of the first episode of grooming $(p=0.03$, $U=58.5)$, lower number of grooming episodes $(p=0.04, U=63.5)$ and shorter duration of grooming behavior $(p=0.02, U=57.0$; Fig. $4 F)$.

\subsubsection{Anxiety-like behavior}

In the O-Maze and Dark/light box paradigms, 18-month-old mice showed non-significantly longer latencies of exit to anxiety-related areas than 3-month-old mice $(p=0.07, d f=20$ and $p=0.69$, $\mathrm{df}=20$, respectively; Fig. $4 \mathrm{G}, \mathrm{J}$ ). Both groups had similar time spent in open arms $(p=0.30, d f=20.0$; Fig. $4 \mathrm{H})$ and lit compartment $(p=0.40, d f=20$; Fig. $4 K)$, as well as number of exits to the open arms $(p=0.43, d f=20$; Fig. $4 \mathrm{I})$ and to the lit box $(p=0.83, d f=20$; Fig. 4L). These data suggest overall similar scores of anxiety-like behavior in 3- and 18-month old mice in employed here testing conditions.

\subsection{Experiment 4: effects of imipramine and dimebon in tests for depressive-like behavior}

\subsubsection{Sucrose preference test}

Baseline testing in the sucrose test (before the onset of chronic drug administration) revealed significantly lower sucrose intake and preference in 18-month-old than in 3-month-old mice $(\mathrm{p}<0.0001$, $\mathrm{U}=2.0$ and $\mathrm{p}=0.0007, \mathrm{U}=6.5$, respectively; data not shown); older animals consumed significantly more water $(p=0.0007, U=6.5)$, but their total liquid intake did not differ from that of younger animals $(p=0.10, U=25.0)$. After chronic dosing, sucrose intake and preference were significantly changed $(\mathrm{p}=0.003$, Kruskal-Wallis statistic $=16.21$ and $\mathrm{p}<0.0001$, Kruskal-Wallis statistic $=25.21$, respectively). In imipramine-treated 18-month-old mice, both parameters were significantly higher than in non-treated mice of this age $(p=0.003, U=2.00$; and $p=0.002, U=0.00$, respectively; Fig. $5 A, B)$. While these parameters were significantly decreased in non-treated 18 versus 3-month-old mice ( $p=0.0007, U=6.5$ and $p<0.0001, U=2.0$, respectively), such differences were not found in aged imipramine-treated groups $(p=0.95, U=24.5$ and $p=0.59, U=20.0)$. Treatment with imipramine did not affect either of these variables in young mice $(\mathrm{p}=0.13$, $\mathrm{U}=19.50$ and $\mathrm{p}=0.36 ; \mathrm{U}=25.0$, respectively).

Similarly to imipramine-treated aged mice, 18-month-old mice dosed with dimebon showed a significantly higher sucrose intake and preference than non-treated mice of this age $(p=0.002, U=7.0$ and $p=0.04, U=17.0$; Fig. $5 A, B$ ). Sucrose intake in aged dimebontreated mice did not differ from that in young mice $(p=0.63$, $U=43.0$ ), while sucrose preference was significantly higher in the 3 -month-old group $(p=0.002, U=11.0)$. The latter effect was due to increased water intake in the dimebon-treated 18-month-old group versus the 18 -month-old non-treated group $(p=0.003$, $U=8.0$ ). Sucrose preference was significantly higher in imipraminetreated than in dimebon-treated 18-month-old mice $(\mathrm{p}=0.001$, $U=1.0)$, while sucrose intake did not differ $(p=0.85, U=23.0)$.

Multiple group comparison indicated that water intake was significantly altered $(p=0.0004$, Kruskal-Wallis statistic $=20.64$, Fig. 5C). Treatment with imipramine did not affect water intake in young animals $(\mathrm{p}=0.31, \mathrm{U}=24.0)$ and decreased this variable in old group $(\mathrm{p}=0.006, \mathrm{U}=2.0)$; as it is mentioned above, dimebon reduced this measure in 18 -month-old mice $(\mathrm{p}=0.003, \mathrm{U}=8.0)$. Multiple group comparison revealed significant changes in total intake of liquids $(p=0.01$ Kruskal-Wallis statistic $=12.55$, Fig. $5 D)$; this parameter was augmented in 18-month-old mice treated with dimebon versus non-treated aged animals $(\mathrm{p}=0.003, \mathrm{U}=8.0)$ and was not changed in imipramine-treated 3-month-old mice $(\mathrm{p}=0.31, \mathrm{U}=24.0)$ nor in 18 -month-old mice ( $p=0.35, U=13.0$, vs. young mice).

\subsubsection{Effects of imipramine and dimebon on measures of affective behavior of young and old mice}

Manual scoring of the forced swim test showed that 3- and 18-month-old imipramine-treated mice had higher latency of floating than non-treated animals (day $1: \mathrm{p}=0.005, \mathrm{U}=8.5$ and $\mathrm{p}=0.08$, $\mathrm{U}=10.0$, day $2: \mathrm{p}=0.008, \mathrm{U}=8$ and $\mathrm{p}=0.007, \mathrm{U}=3$, respectively; Fig. 5E,F). No difference between dimebon-treated and non-treated groups of old mice in this parameter was revealed (day $1: \mathrm{p}=0.93$, $U=38.5$, day $2: p=0.79, U=36.5$ ). Experimental groups 3 - and 18 month-old mice treated with imipramine showed significantly decreased duration of floating than non-treated control animals (day 1: $p=0.03, U=16.0$ and $p=0.04, U=12.50$; day $2(p=0.004, U=6.0$ and $p=0.005, U=3.0$, respectively). A comparison of scores of floating measured in dimebon-treated and non-treated 18-month-old mice did 
FORCED SWIM TEST DAY 1
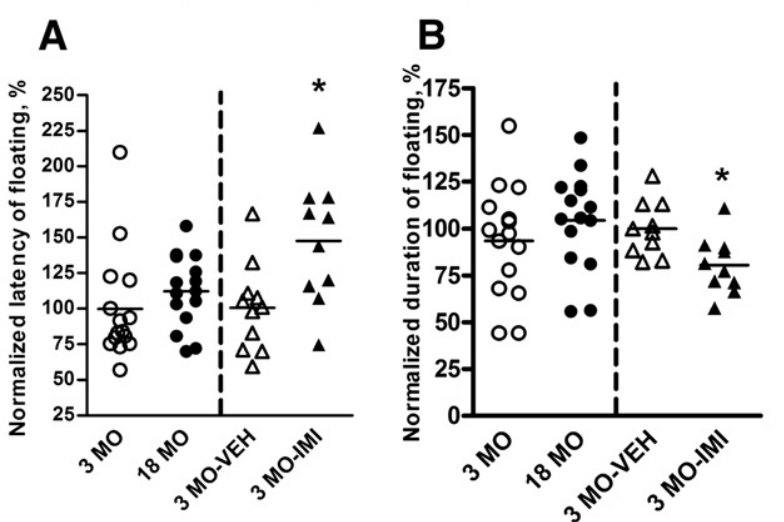

TAIL SUSPENSION TEST DAY 1
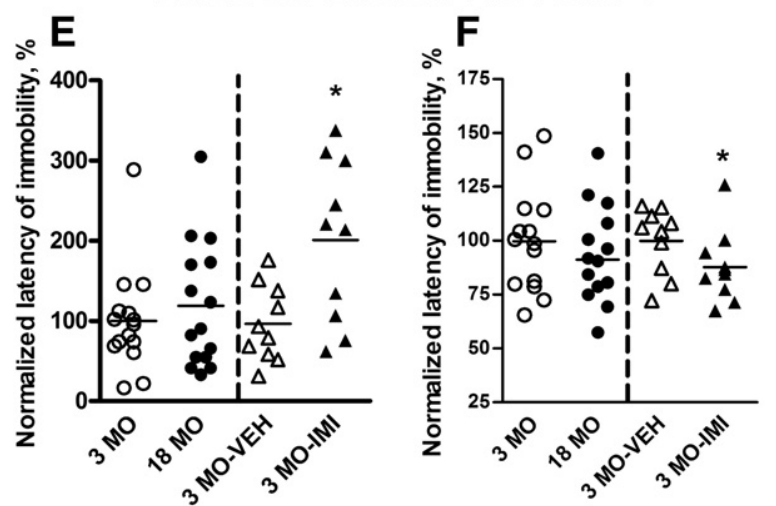
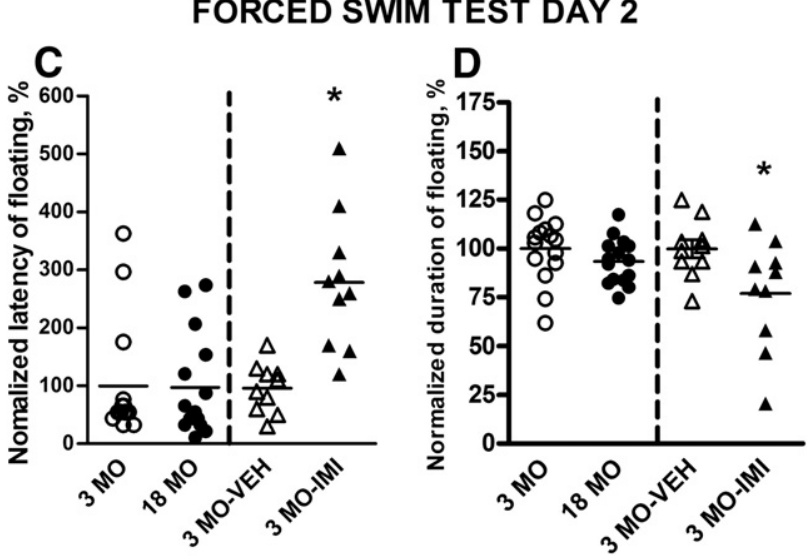

TAIL SUSPENSION TEST DAY 2
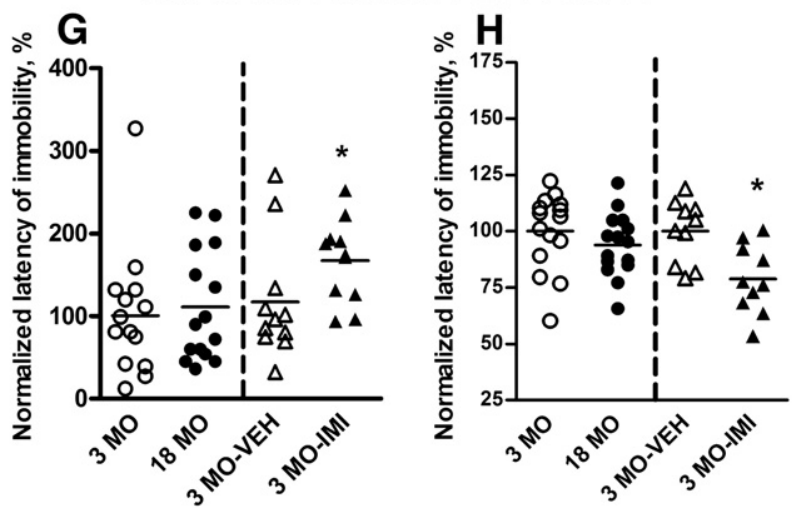

Fig. 3. Similar floating and immobility behaviors of visually scored 3- and 18-month-old mice. On both day 1 (A) and day 2 (C) of the forced swim test, imipramine-treated group had elevated latency of floating $\left({ }^{*} \mathrm{p}<0.05\right.$, vs. vehicle-treated and $\# \mathrm{p}<0.05$, vs. non-treated 3-month-old mice); 3- and 18-month-old mice had a similar latency of floating ( $\mathrm{p}>0.05$; Mann-Whitney $U$-test). On day 1 (B) and day 2 (D), duration of floating was lower in imipramine-treated group $\left({ }^{*} \mathrm{p}<0.05\right.$, vs. vehicle-treated and \#p $<0.05$, vs. non-treated 3-monthold mice); and did not differ between 3- and 18-month-old animals ( $\mathrm{p}>0.05$; Mann-Whitney U-test). In the modified tail suspension test, on both day 1 (E) and day 2 (G), imipramine-treated group had elevated latency of immobility ( ${ }^{*} \mathrm{p}<0.05$, vs. vehicle-treated and $\# \mathrm{p}<0.05$, vs. non-treated 3-month-old mice); 3- and 18 -month-old mice had a similar latency of immobility ( $\mathrm{p}>0.05$; Mann-Whitney $U$-test). On day $1(\mathrm{~F})$ and day $2(\mathrm{H})$, duration of immobility was lower in imipramine-treated group ( ${ }^{*} \mathrm{p}<0.05$, vs. vehicle-treated and $\# \mathrm{p}<0.05$, vs. non-treated 3-month-old mice); and did not differ between 3- and 18-month-old animals ( $\mathrm{p}>0.05$; Mann-Whitney U-test). Bars represent the means. 3 MO: 3-monthold mice $(\mathrm{n}=15)$; $18 \mathrm{MO}$ : 18-month-old mice $(\mathrm{n}=15)$; 3 MO-VEH: vehicle-treated 3-month-old mice $(\mathrm{n}=10)$; 3 MO-IMI: imipramine-treated 3-month-old mice ( $\mathrm{n}=10)$.

not reveal any differences between the groups (day 1: $\mathrm{p}=0.73$, $\mathrm{U}=31.0$; day 2: $\mathrm{p}=0.89, \mathrm{U}=38.0$ ).

Similarly to the outcome of the forced swim test, manual analysis of the modified tail suspension test revealed the differences between the same groups. Young and aged imipramine-treated mice showed significantly longer latencies of the immobility as compared with non-treated control groups (on day $1: \mathrm{p}=0.04, \mathrm{U}=17.5$ and $\mathrm{p}=0.02, \mathrm{U}=7.0$ and day $2: \mathrm{p}=0.04, \mathrm{U}=17.5$ and $\mathrm{p}=0.02, \mathrm{U}=4.0$ respectively; Fig. 5G,H). No difference between dimebon-treated and non-treated groups of old mice in this parameter was found (day 1: $\mathrm{p}=1.0, \mathrm{U}=31.5$, day $2: \mathrm{p}=0.86, \mathrm{U}=37.5$ ). Imipraminetreated 3 - and 18-month-old mice showed significantly decreased duration of immobility as compared with non-treated control animals (day 1: $\mathrm{p}=0.01, \mathrm{U}=12.0$ and $\mathrm{p}=0.04, \mathrm{U}=8.0$, and day $2: \mathrm{p}=0.008$, $\mathrm{U}=8.0$ and $\mathrm{p}=0.003, \mathrm{U}=2.0$ respectively). This parameter was not changed in old mice treated with dimebon as compared with nontreated animals of that age (day $1: p=0.89, U=38.0$; day 2 : $\mathrm{p}=0.45, \mathrm{U}=31.0$ ).

\section{Discussion}

4.1. Anhedonic-like traits of older mice and their reversal by antidepressant treatment

In a $1 \%$ sucrose preference test, 18 -month-old mice showed significantly reduced sucrose intake and preference (Fig. 1A,F) that were previously shown to correlate with features of depression in stressed C57BL/6N mice (Strekalova and Steinbusch, 2009, 2010; Strekalova et al., 2008, 2011; Strekalova, 2008; Tokarski et al., 2009). Such abnormalities were not observed in a subset of stressed resilient mice whose sucrose intake and preference was preserved during stress, nor in stressed animals chronically treated with antidepressants imipramine or citalopram. From that, the data obtained here suggest hedonic deficit in 18-month-old mice. Restoration of normal sucrose intake and preference in these animals by a 4 -week treatment with the classical antidepressant imipramine (Fig. 5A,B) supports this suggestion. Importantly, the decrease in sucrose preference in 18-monthold mice occurred at the expense of both a reduction in sucrose intake (Fig. 1B) and an increase in water consumption (Fig. 1C); the latter effect was compensatory, as the total liquid intake and 24-h water consumption was unaltered. The concomitance of a decrease in sucrose intake and preference additionally points to the occurrence of anhedonia in older mice.

The amount of highly palatable $5 \%$ sucrose solution consumed in a high-effort drinking paradigm was significantly lower in 18-monthold mice (Fig. 1G); such effects in analogous paradigms are regarded as a sign of decreased hedonic sensitivity (Hsiao and Chen, 1995). The similar intake of water in the two groups rules out a potential physical deficit as a possible confound in the assay. Comparable intake values of a $5 \%$ - sucrose solution in non-restricted drinking conditions in two groups suggest them to be equally capable of tasting a sucrose solution. Thus, diminished intake of sucrose solution by aged animals 


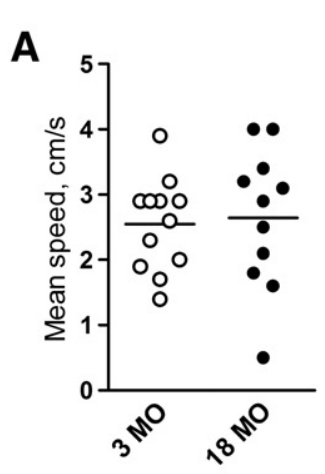

NOVEL CAGE
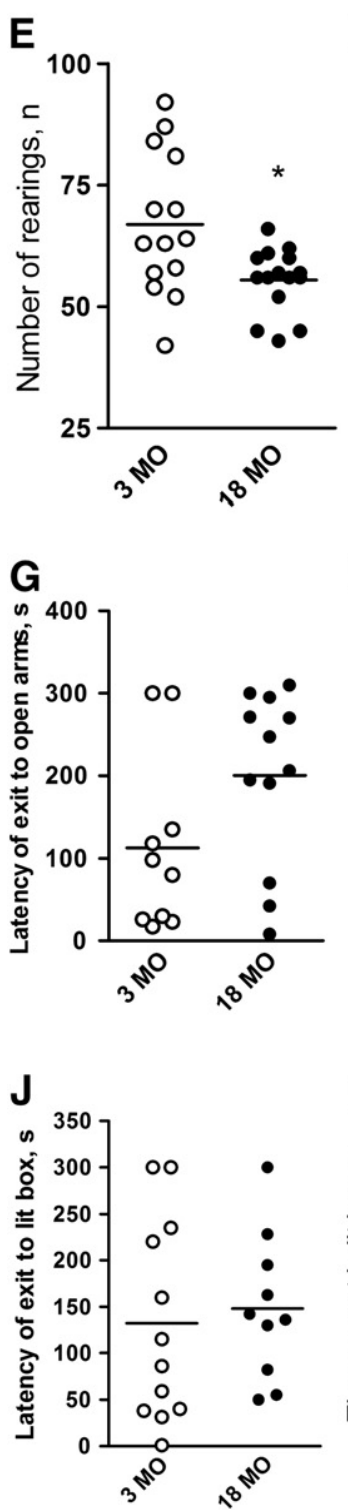
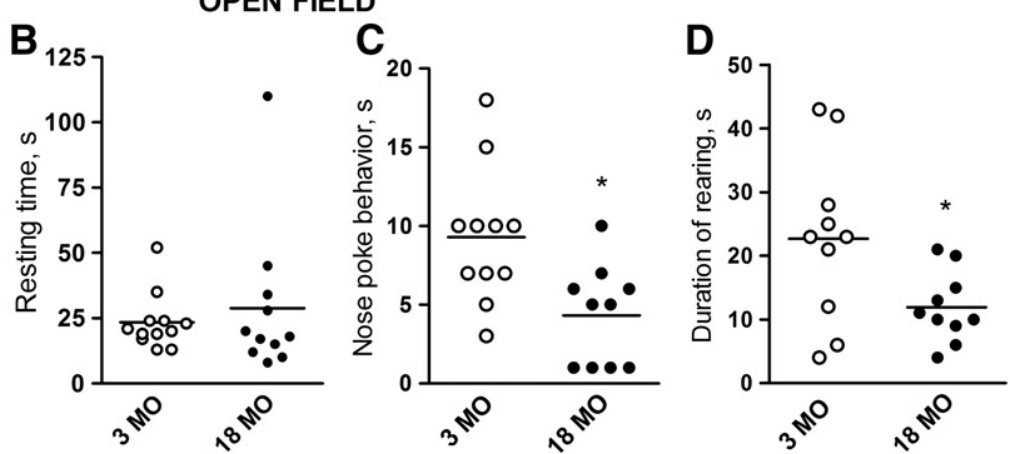

\section{SPLASH TEST}

$\mathbf{F}$
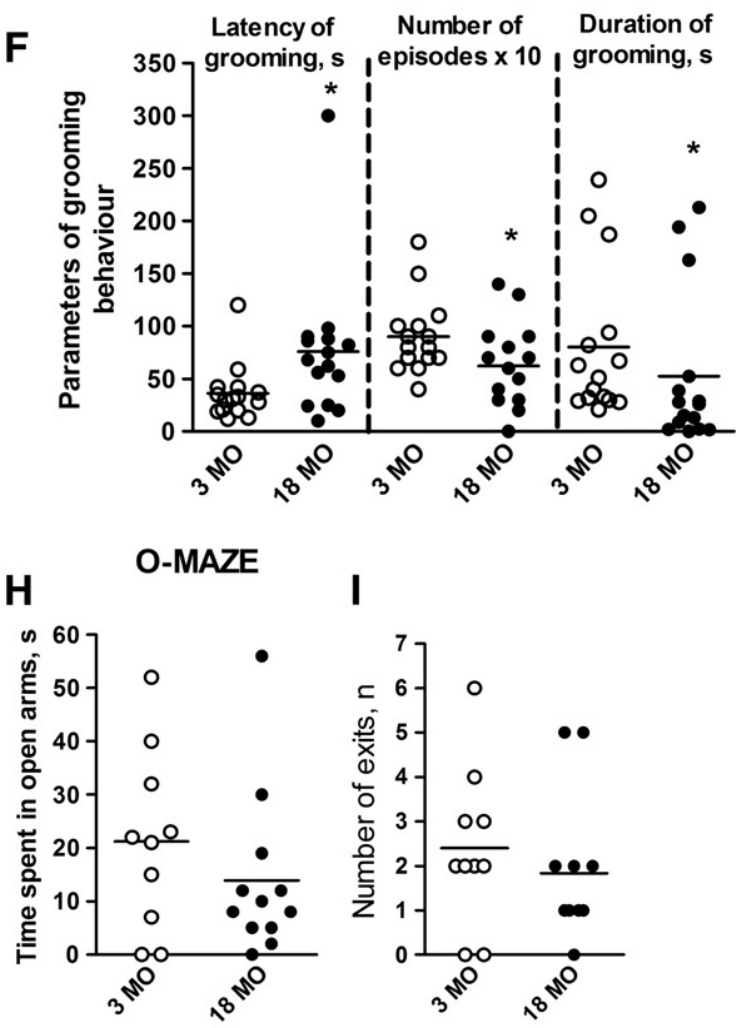

I

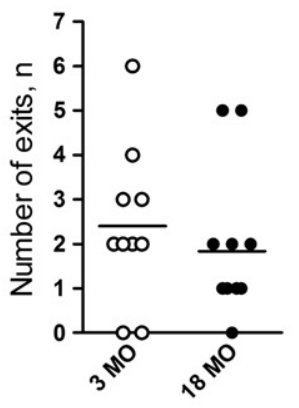

DARK / LIGHT BOX
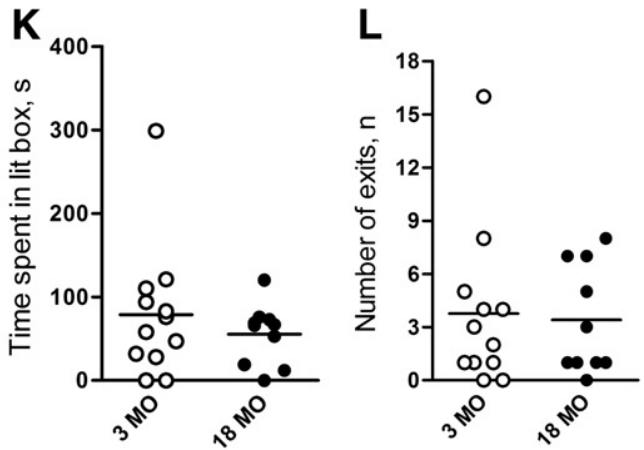

Fig. 4. Parameters of locomotion, exploration, grooming and anxiety-like behavior in 3-versus 18-month-old mice. Mean speed (A) and resting time (B) were similar in old and young mice ( $p>0.05$; unpaired $t$-test). In comparison to young mice, older mice displayed a significantly shorter duration of nose poke behavior (C) and rearing activity (D) in the open-field test $\left({ }^{*} \mathrm{p}<0.05\right.$; unpaired $t$-test $)$, and fewer rearings in the novel cage test $(\mathrm{E})\left({ }^{*} \mathrm{p}<0.05\right.$; unpaired $t$-test). ( $\left.\mathrm{F}\right) 18$-month-old mice showed higher latency of the first episode of grooming, lower number and duration of grooming episodes than 3-month-old mice ( ${ }^{*} \mathrm{p}<0.05$; Mann-Whitney $U$-test). In the 0 -Maze test, in comparison with 3-month-old mice, 18-month-old animals showed non-significantly longer latencies of exit to the open arms (G) and similar values of time spent therein (H) and number of exits to this area (I) ( $p>0.05$; unpaired $t$-test). In the dark/light box, there were no differences between the groups in latency of exit to the lit compartment (J) time spent in this zone $(\mathrm{K})$ or the number of exits to the illuminated box $(\mathrm{L})(p>0.05$; unpaired $t$-test). Bars represent the means. 3 MO: 3-month-old mice $(\mathrm{A}-\mathrm{E}$ and $\mathrm{G}-\mathrm{L}$ : $\mathrm{n}=12$; F: $\mathrm{n}=15)$; 18 MO: 18-month-old mice (A-E and G-L: $\mathrm{n}=11 ; \mathrm{F}: \mathrm{n}=15$ ). 
SUCROSE TEST
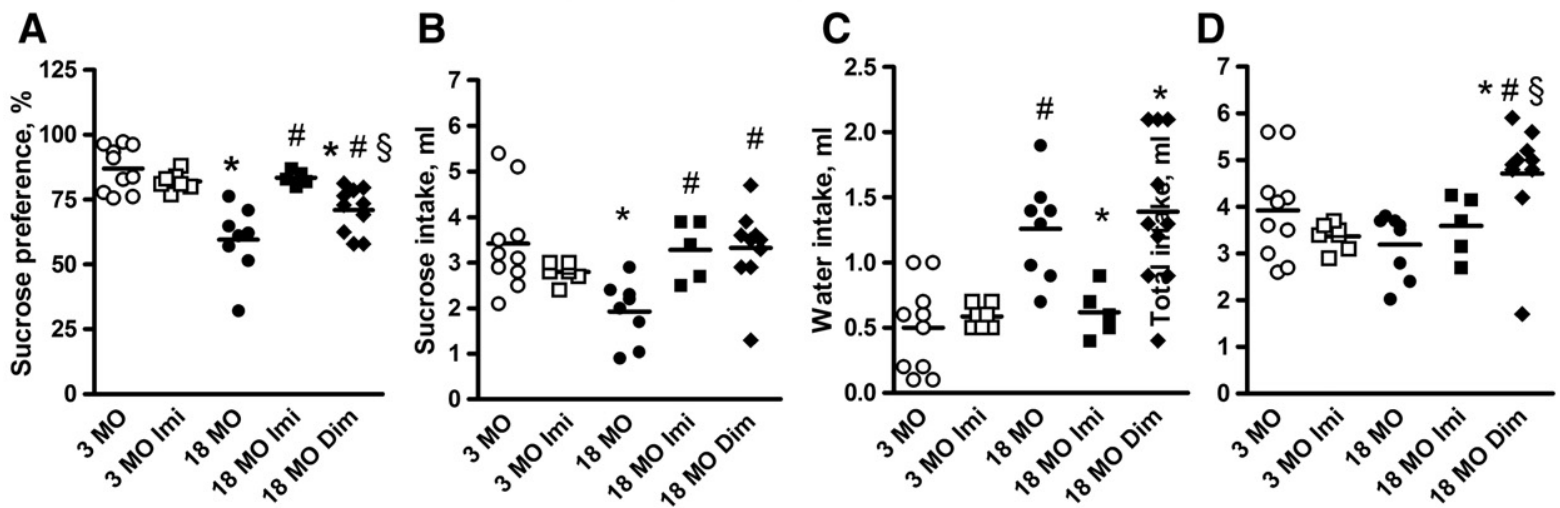

FORCED SWIM TEST
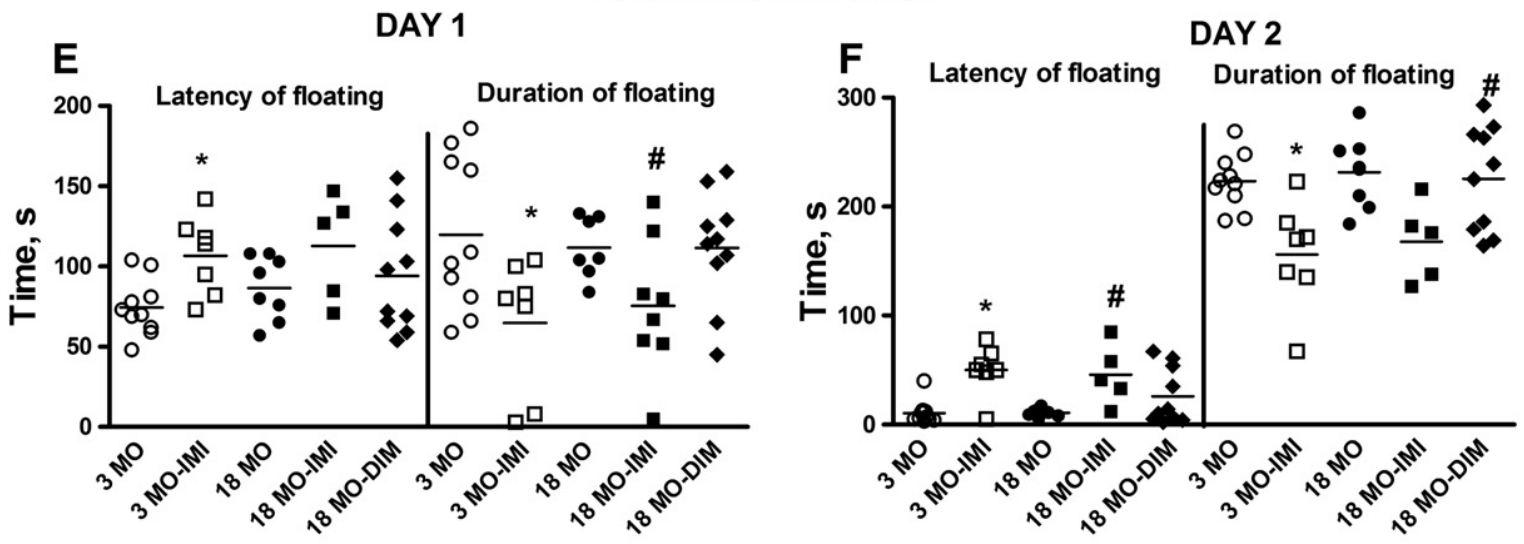

TAIL SUSPENSION TEST

DAY 1

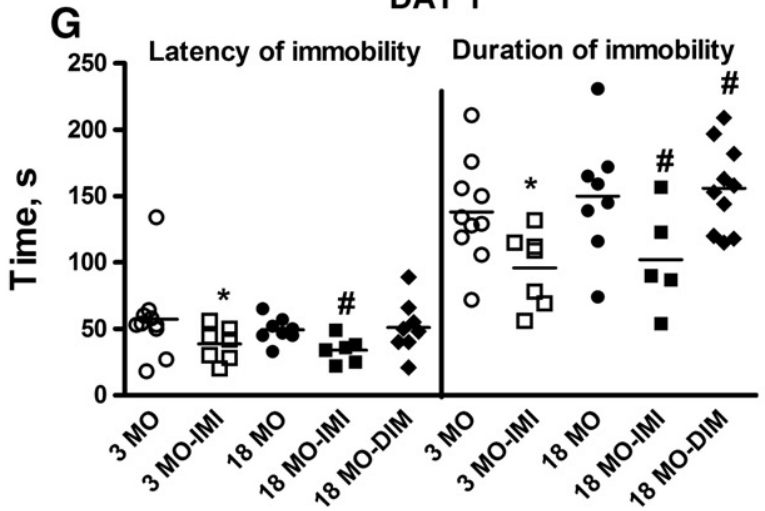

DAY 2

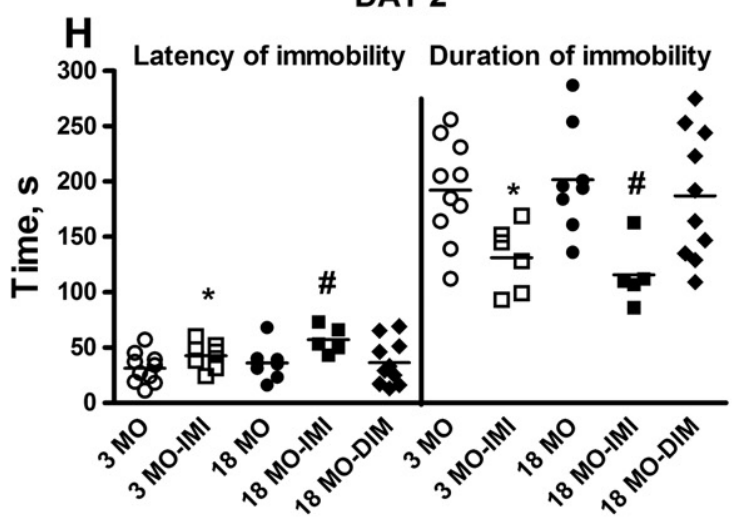

Fig. 5. (A) Sucrose preference was decreased in non-treated older animals ( ${ }^{*} p<0.05$, old vs. young mice; Mann-Whitney U-test), but not in 18 -month-old mice treated with imipramine $(p>0.05)$; it was significantly elevated in both treated groups ( $\# p<0.05$, vs. 18-month-old non-treated group; Mann-Whitney U-test). Dimebon-treated 18-month-old group had significantly lower sucrose preference than young mice $\left({ }^{*} p<0.05\right.$; Mann-Whitney U-test) and mice of this age that received imipramine $(\S p<0.05$; Mann-Whitney Utest). (B) Sucrose intake was significantly reduced in older group $\left({ }^{*} p<; 0.05\right.$, Mann-Whitney U-test), while aged imipramine- and dimebon-treated animals did not differ from young mice ( $p>0.05$, vs. 3-month-old mice); sucrose intake was similar in the latter two groups ( $p>0.05$, Mann-Whitney) and significantly higher in these groups compared to non-treated aged mice (\#p<0.05, vs. 18-month-old non-treated group; Mann-Whitney U-test). (C) Aged non-treated and dimebon-treated mice showed enhanced water intake in comparison with young mice $\left({ }^{*} p<0.05\right.$, Mann-Whitney U-test); this was not found in imipramine-treated animals treated with imipramine, which showed a significant decrease in this measure in comparison to the two other 18-month-old groups ( $\# p<0.05$; Mann-Whitney U-test). Young imipramine-treated mice had no changes in water consumption compared to the non-treated animals ( $p>0.05$, Mann-Whitney). (D) Total liquid intake was elevated in all groups of old mice in comparison to young mice ( ${ }^{*} p<0.05$ for dimebon-treated mice, $\# p<0.05$ for non-treated and $\$ p<0.05$ for imipramine-treated mice). Young imipramine-treated mice showed no differences in this parameter. (E) Imipramine-treated mice of both ages had longer latency of floating and (F) decreased duration of floating on days 1 and 2 than non-treated groups ( ${ }^{*} p<0.05$, Mann-Whitney U-test). There were no changes in floating in dimebon-treated old mice ( $p>0.05$, Mann-Whitney). In the modified tail suspension test, the latency of immobility ( $G$ ) was significantly longer and $(\mathrm{H})$ the duration of immobility was significantly shorter in imipramine-treated mice of both ages $\left({ }^{*} p<0.05\right.$, Mann-Whitney U-test). Older animals treated with dimebon had no changes in parameters of immobility ( $p>0.05$, Mann-Whitney). Bars represent the means. 3 MO: non-treated 3-month-old mice ( $\mathrm{n}=10$ ); 3 MO-IMI: 3-month-old mice treated with imipramine $(\mathrm{n}=7)$; 18 MO: 18-month-old mice $(\mathrm{n}=8)$; 18 MO-IMI: 18-month-old mice treated with imipramine ( $\mathrm{n}=5)$; 18 MO-DIM: 18-month-old mice treated with dimebon $(n=10)$. 
is likely to be due to their lower motivation for pleasurable stimulation rather than impaired ability to drink from narrow tips or taste a sweet.

The lack of change in total liquid intake in the sucrose test and 24-h water consumption in this group (Figs. 1D, 5D) indicates that its physiological need for water is not altered and cannot account for the observed changes in the sucrose test. The significantly higher body mass in aged mice (Fig. 1E) suggests that the decrease in sucrose intake is not related to changes in caloric needs; besides, the sucrose test parameters were shown to be unrelated to individual body weights (Strekalova et al., 2011). Moreover, 3- and 18-month-old mice displayed similar scores for locomotion and anxiety (Fig. 4A,C-G). This is consistent with the unchanged drinking behavior in novel testing conditions of a high-effort drinking paradigm, showing no indications for neophobia and psychomotor deficits in aged mice (Fig. 1F). These measurements rule out any essential interference of metabolic, motor and emotional changes with the evaluation of proposed anhedonic-like behavior of 18-month-old mice.

Remarkably, 18-month-old mice displayed less nose-poking behavior and a shorter duration of exploratory rearing activity in the open-field test, as well as fewer rearings in the novel cage test (Fig. 4B-D). Low interest in novelty is regarded as reflecting diminished sensitivity to reward/motivation for hedonic stimulation; it parallels elderly depression (Gallo et al., 1997; Bourin et al., 1998) and can be reversed by antidepressant therapy (Willner, 2005; van Miegem et al., 2009; American Psychiatric Association, 2000). This feature generally correlates with aging in rodents (Skrinskaia and Nikulina, 1994; Schulz et al., 2007; Meier et al., 2010; Soffié et al., 1992) and particularly with the occurrence of stress-induced anhedonic behavior in C57BL6N mice (Strekalova et al., 2004; Porsolt and Papp, 1998). Thus, data on superficial exploration of 18 -month-old mice indirectly support the outcome of the sucrose test.

\subsection{Reduced grooming of 18-month-old mice in a splash test}

Similarly to the effects of chronic mild stress (Pothion et al., 2004; Surget et al., 2008), aging was found to result in suppressed grooming behavior in a classical splash test model: 18-month-old mice exhibited significantly shorter duration of grooming behavior than 3-month-old animals (Fig. 4F). This feature has been reported to correlate with key manifestations of a depressive-like state in mice, such as physical appearance, the choice test, deterioration of the fur state, vanilla pasta test, reward maze test and others that extensively validate this effect as an important trait of depressive-like syndrome in mice (Willner, 2005). Similar findings were reported by other groups (Scimonelli et al., 1999; Shoji and Mizoguchi, 2011). Together, these results are consistent with the above manifestations of depressive-like features of older mice in sucrose and exploration tests.

\subsection{Eighteen-month-old mice display no behavioral signs of affective disturbances}

Both manual and automated scoring of the forced swim and modified tail suspension tests, whose protocols were validated in the present study and in other experiments with various antidepressants under a number of conditions (van Miegem et al., 2009; Strekalova et al., 2005, 2006, 2008; Ducottet et al., 2004; Cryan et al., 2005a; Mineur et al., 2006; Vaugeois et al., 1997; Gavioli et al., 2004; Cryan et al., 2005b; Ibarguen-Vargas et al., 2009), revealed the lack of differences between 3- and 18-month-old animals in terms of floating and immobility measured either during the entire 6 -min period (Figs. 2, 3, 5) or over 1- or 2-min intervals (data not shown). Other behaviors, such as the duration of swimming behavior/activity (Fig. 2A,D) and the latency of the first episode of floating/immobility (Fig. 3A,E) also showed no difference between groups. Furthermore, the duration of climbing behavior and diving events during forced swimming, which were shown to be sensitive to some types of antidepressant treatment (Hayashi et al., 2011), did not differ between the two groups (Fig. 3B,C). The latter parameter, however, was significantly more variable in 18-month-old mice, with a non-significant increase (Fig. 3C) that suggests a trend towards psychomotor disturbances in animals of this age. In summary, 18-month-old mice of the C57BL6/N strain did not demonstrate changes in measures for affective behaviors in the forced swim and modified tail suspension test.

Other reports are consistent with our data. Aging did not change the floating behavior of CC57Br, A/He and $\mathrm{C} 3 \mathrm{H} / \mathrm{He}$, which were tested at the age of about 15 months (Skrinskaia and Nikulina, 1994). A lack of differences in mobility scores in the modified tail suspension and forced swim tests was reported in 10- to 15-month-old C57BL6 mice (David et al., 2001; Bourin et al., 1998; Ohashi et al., 2006). Studies that were predominantly performed on rodents of older age, however, reported increased floating and immobility behaviors; the various outcomes in these tests can be accounted for by the different age categories. Since most of them evidence higher scores of behavioral despair accompanied by psychomotor deficits, the validity of these findings may be limited (Skrinskaia and Nikulina, 1994; Schulz et al., 2007; Soffié et al., 1992; Bowman et al., 2006).

\subsection{Comparison of 3- and 18-month-old mice in additional tests}

Similar values for the speed of movement and resting time in the open-field test suggest a lack of motor disturbances in 18-monthold mice (Fig. 4A,B). The onset, frequency and duration of grooming, as well as nose-poking behavior, exploratory rearing, and vertical activity in the novel cage test were inhibited in 18-month-old mice, in comparison to a younger group (Fig. 4C-F). As discussed above, decreases in these behaviors parallel reduced hedonic sensitivity and other depressive-like features in rodents. Elevated anxiety is a well-known feature of aging and depressive disorder (American Psychiatric Association, 2000), but not always accompanies anhedonia/depressive syndrome in clinical and animal studies (Hybels et al., 2011; Pachana et al., 2011; Sobrian et al., 2003). Our experiments found no evidence of such changes in 18-month-old mice (Fig. 4G-L). This may be due to the applied here "mild" protocols of the O-Maze and dark/light box anxiety paradigms (Strekalova et al., 2005, 2006), while most of studies which reported increased anxiety-like behavior during aging, employ highly anxiogenic testing (Skrinskaia and Nikulina, 1994; Schulz et al., 2007; Meier et al., 2010; Lawton et al., 1996). In summary, in the protocols used here for anxiety-like behaviors and other behavioral analysis, aged mice displayed no alterations in measures of anxiety-like behavior and locomotion, excluding possible confounds with evaluation of depressive-like traits.

\subsection{Effects of imipramine and dimebon in old mice}

Both drugs elevated sucrose intake and preference in 18-month-old mice (Fig. 5B) that is characteristic of the effects of antidepressants (Porsolt and Papp, 1998; Strekalova et al., 2011; van Miegem et al., 2009). Thus, elderly-related manifestations of anhedonia are reversible by antidepressant treatment with imipramine that validates the proposed model pharmacologically. In contrast to imipramine, dimebontreated mice showed a significant increase in the total intake of liquid (Fig. 5D) that may suggest the emergence of the characteristic antihistamine effect of increasing water intake, reported in patients after a four-week course of dimebon, and in mice after five-day treatment, at comparable doses (Vignisse et al., 2011; Bachurin and Grigoriev, 2008; Magrani et al., 2006). Imipramine reduced water intake that was obviously owed to the compensation of increased consumption of a sucrose solution (Fig. 5A-C). Interestingly, dimebon exhibited anti-anxiety effects in mice and rats (Vignisse et al., 2011; Magrani et al., 2006), which similarly to the situation with many other drugs, overlap with its antidepressant action (Porsolt and Papp, 1998; Willner, 2005). 
Further experiments are required to see whether one of the abovediscussed mechanisms (Bolkunov et al., 2009; Strekalova, 2008; Strekalova and Steinbusch, 2009; Hybels et al., 2011; Bachurin et al., 2001,2003 ) or other effects of dimebon underlie its activity in sucrose test.

In the modified protocols of the forced swim and modified tail suspension tests, imipramine but not dimebon decreased duration of floating and immobilization during testing on both days (Fig. 5D,E). These effects were found in both young and old mice. The latency of the first episode of floating was also decreased by imipramine in mice of both ages; no such effect was found in dimebon-treated mice. Thus, the effects of antidepressant treatment in the tests for animal parallels behavioral despair where originally 3 - and 18-monthold mice display similar behavior did not differ between the groups.

\section{Conclusions}

The present study demonstrates the occurrence of anhedonic-like traits in 18-month-old mice which are not accompanied by manifestations of behavioral despair and mimic the clinical profile of primary elderly depression where hedonic deficits outweigh affective symptoms. Anhedonic-like changes in older mice found in a sucrose preference test were sensitive to a chronic antidepressant treatment and were accompanied by decreases in sucrose intake in a high-effort drinking paradigm, grooming in a splash test and novelty exploration. Additional studies ruled out potential confounds in the analysis of behavioral features that are specific to depressive-like syndrome, in pre-clinical modeling of elderly depression in 18-months-old mice of this strain.

\section{Acknowledgments}

We would like to thank Vincent van Miegem, Natalia Markina and Joao Nunes for excellent technical assistance, Dr. Gennadii Vankin for valuable scientific input to this study, and Dr. Brandon $\mathrm{H}$. Cline for kind help with improving the English. We are especially grateful to CleverSys for providing us with free access to software. This work was supported by ISAO N 09501 to T.S., NARSAD 17611 to T.S, RFBR 11-04-01411 and DAAD 2006 to N.Y.

\section{References}

American Psychiatric Association, 2000. American Psychiatric Association, Diagnostic and Statistical Manual for Mental Disorders, 4th edition. American Psychiatry Press Inc., Washington DC.

Bachurin, S.O., 2003. Medicinal chemistry approaches for the treatment and prevention of Alzheimer's disease. Med. Res. Rev. 23, 48-88.

Bachurin, S.O., Grigoriev, V.V., 2008. A drug demonstrating anxiolytic effect based on hydrogenated pyrido (4,3-B) indoles, its pharmacological compound and application method WO2009005771 (A1).

Bachurin, S., Bukatina, E., Lermontova, N., Tkachenko, S., Afanasiev, A., Grigoriev, V., Grigorieva, I., Ivanov, Y., Sablin, S., Zefirov, N., 2001. Antihistamine agent Dimebon as a novel neuroprotector and a cognition enhancer. Ann. N. Y. Acad. Sci. 939, 425-435.

Bachurin, S., Shevtsova, E., Kireeva, E., Oxenkrug, G., Sablin, S., 2003. Mitochondria as a target for neurotoxins and neuroprotective agents. Ann. N. Y. Acad. Sci. 993, 334-344.

Bernales, S., Alarcon, R., Guerrero, J., Higaki, J.N., Protter, A.A., 2009. Dimebon induces neurite outgrowth from hippocampal, spinal, and cortical neurons. Neurology 72, A 385 .

Blanton, C.A., Horwitz, B.A., Murtagh-Mark, C., Gietzen, D.W., Griffey, S.M., McDonald, R.B., 1998. Meal patterns associated with the age-related decline in food intake in the Fischer 344 rat. Am. J. Physiol. 275, R1494-R1502.

Bolkunov, A., Redkozubova, O., Malatynska, E., van Miegem, V., Vankin, G., Strekalova, T., Bachurin, S., 2009. Aging-related anhedonia in C 57 mice and effects of dimebone. J. Neurochem. 110 (S1), 50.

Bourin, M., Colombel, M.C., Redrobe, J.P., Nizard, J., Hascoët, M., Baker, G.B., 1998. Evaluation of efficacies of different classes of antidepressants in the forced swimming test in mice at different ages. Prog. Neuropsychopharmacol. Biol. Psychiatry 22, 343-351.

Bowman, R.E., Maclusky, N.J., Diaz, S.E., Zrull, M.C., Luine, V.N., 2006. Aged rats: sex differences and responses to chronic stress. Brain Res. 1126, 156-166.
Campbell, J.O., Wood, R.D.R.D., 2000. Cocaine and morphine-induced place conditioning in adolescent and adult rats. Physiol. Behav. 68, 487-493.

Cryan, J.F., Valentino, R.J., Lucki, I., 2005a. Assessing substrates underlying the behavioural effects of antidepressants using the modified rat forced swimming test. Neurosci. Biobehav. Rev. 29, 547-569.

Cryan, J.F., Mombereau, C., Vassout, A., 2005b. The tail suspension test as a model for assessing antidepressant activity: review of pharmacological and genetic studies in mice. Neurosci. Biobehav. Rev. 29, 571-625.

David, D.J., Bourin, M., Hascoët, M., Colombel, M.C., Baker, G.B., Jolliet, P., 2001. Comparison of antidepressant activity in 4- and 40-week-old male mice in the forced swimming test: involvement of 5-HT1A and 5-HT1B receptors in old mice. Psychopharmacology (Berl) 153, 443-449.

Doody, R.S., Gavrilova, S.I., Sano, M., Thomas, R.G., Aisen, P.S., Bachurin, S.O., Seely, L., Hung, D., 2008. Effect of dimebon on cognition, activities of daily living, behaviour, and global function in patients with mild-to-moderate Alzheimer's disease: a randomized, double-blind, placebo-controlled study. Lancet 372, 207-215.

Dubreucq, S., Koehl, M., Abrous, D.N., Marsicano, G., Chaouloff, F., 2010. CB1 receptor deficiency decreases wheel-running activity: consequences on emotional behaviours and hippocampal neurogenesis. Exp. Neurol. 224, 106-113.

Ducottet, C., Aubert, A., Belzung, C., 2004. Susceptibility to subchronic unpredictable stress is related to individual reactivity to threat stimuli in mice. Behav. Brain Res. 155, 291-299.

Fonken, L.K., Finy, M.S., Walton, J.C., Weil, Z.M., Workman, J.L., Ross, J., Nelson, R.J., 2009. Influence of light at night on murine anxiety- and depressive-like responses. Behav. Brain Res. 205, 349-354.

Frye, C.A., Walf, A.A., 2009. Depression-like behaviour of aged male and female mice is ameliorated with administration of testosterone or its metabolites. Physiol. Behav. 97, 266-269.

Gallo, J.J., Anthony, J.C., Muthén, B.O., 1994. Age differences in the symptoms of depression: a latent trait analysis. J. Gerontol. 49, 251-264.

Gallo, J.J., Rabins, P.V., Lyketsos, C.G., Tien, A.Y., Anthony, J.C., 1997. Depression without sadness: functional outcomes of nondysphoric depression in later life. J. Am. Geriatr. Soc. 45, 570-578.

Gavioli, E.C., Vaughan, C.W., Marzola, G., Guerrini, R., Mitchell, V.A., Zucchini, S., De Lima, T.C., Rae, G.A., Salvadori, S., Regoli, D., Calo', G., 2004. Antidepressant-like effects of the nociceptin/orphanin FQ receptor antagonist UFP-101: new evidence from rats and mice. Naunyn Schmiedebergs Arch. Pharmacol. 369, 547-553.

Glaesmer, H., Riedel-Heller, S., Braehler, E., Spangenberg, L., Luppa, M., 2011. Age- and gender-specific prevalence and risk factors for depressive symptoms in the elderly: a population-based study. Int. Psychogeriatr. 17, 1-7.

Godbout, J.P., Moreau, M., Lestage, J., Chen, J., Sparkman, N.L., O' Connor, J., Castanon, N., Kelley, K.W., Dantzer, R., Johnson, R.W., 2008. Aging exacerbates depressive-like behaviour in mice in response to activation of the peripheral innate immune system. Neuropsychopharmacology 33, 2341-2351.

Gómez-Lázaro, E., Arregi, A., Beitia, G., Vegas, O., Azpiroz, A., Garmendia, L., 2011. Individual differences in chronically defeated male mice: Behavioural, endocrine, immune, and neurotrophic changes as markers of vulnerability to the effects of stress. Stress 15, 537-548.

Gould, T.J., Feiro, O.R., 2005. Age-related deficits in the retention of memories for cued fear conditioning are reversed by galantamine treatment. Behav. Brain Res. 165, 160-171.

Hamilton, M., 1967. Development of a rating scale for primary depressive illness. Br. J. Soc. Clin. Psychol. 6, 278-296.

Hayashi, E., Shimamura, M., Kuratani, K., Kinoshita, M., Hara, H., 2011. Automated experimental system capturing three behavioural components during murine forced swim test. Life Sci. 88, 411-417.

Herrera-Pérez, J.J., Martínez-Mota, L., Fernández-Guasti, A., 2008. Aging increases the susceptibility to develop anhedonia in male rats. Prog. Neuropsychopharmacol. Biol. Psychiatry 32, 1798-1803.

Herrera-Pérez, J.J., Martínez-Mota, L., Fernández-Guasti, A., 2010. Aging impairs the antidepressant-like response to citalopram in male rats. Eur. J. Pharmacol. 633, 39-43.

Hsiao, S., Chen, B.H., 1995. Complex response competition and dopamine blocking: choosing of high cost sucrose solution versus low cost water in rats. Chin. J. Physiol. 38, 99-109.

Hybels, C.F., Landerman, L.R., Blazer, D.G., 2011. Age differences in symptom expression in patients with major depression. Int. J. Geriatr. Psychiatry. http://dx.doi.org/ 10.1002/gps.2759.

Ibarguen-Vargas, Y., Surget, A., Vourc'h, P., Leman, S., Andres, C.R., Gardier, A.M., Belzung, C., 2009. Deficit in BDNF does not increase vulnerability to stress but dampens antidepressant-like effects in the unpredictable chronic mild stress. Behav. Brain Res. 202, 245-251.

Kanarik, M., Alttoa, A., Matrov, D., Kõiv, K., Sharp, T., Panksepp, J., Harro, J., 2011. Brain responses to chronic social defeat stress: effects on regional oxidative metabolism as a function of a hedonic trait, and gene expression in susceptible and resilient rats. Eur. Neuropsychopharmacol. 21, 92-107.

Klein, D.F., 1974. Endogenomorphic depression. A conceptual and terminological revision. Arch. Gen. Psychiatry 31, 447-454.

Lawton, M.P., Parmelee, P.A., Katz, I.R., Nesselroade, J., 1996. Affective states in normal and depressed older people. J. Gerontol. B Psychol. Sci. Soc. Sci. 51, 309-316.

Lermontova, N.N., Lukoyanov, N.V., Serkova, T.P., Lukoyanova, E.A., Bachurin, S.O., 2000. Dimebon improves learning in animals with experimental Alzheimer's disease. Bull. Exp. Biol. Med. 129, 544-546.

Magrani, J., de Castro E Silva, E., Athanazio, R., Improta, L., Fregoneze, J.B., 2006. Involvement of central $\mathrm{H} 1$ and $\mathrm{H} 2$ receptors in water intake induced by hyperosmolarity, hypovolemia and central cholinergic stimulation. Physiol. Behav. 89, 241-249. 
Marcocci, L., De Marchi, U., Salvi, M., Milella, Z.G., Nocera, S., Agostinelli, E., Mondovi, B. Toninello, A., 2002. Tyramine and monoamine oxidase inhibitors as modulators of the mitochondrial membrane permeability transition. J. Membr. Biol. 188, 23-31.

Meier, I., Fellini, L., Jakovcevski, M., Schachner, M., Morellini, F., 2010. Expression of the snoRNA host gene gas5 in the hippocampus is upregulated by age and psychogenic stress and correlates with reduced novelty-induced behaviour in C57BL/6 mice. Hippocampus 20, 1027-1036.

Mineur, Y.S., Belzung, C., Crusio, W.E., 2006. Effects of unpredictable chronic mild stress on anxiety and depression-like behaviour in mice. Behav. Brain Res. 175, 43-50.

Moretti, M., de Souza, A.G., de Chaves, G., de Andrade, V.M., Romao, P.R., Gavioli, E.C. Boeck, C.R., 2011. Emotional behaviour in middle-aged rats: implications for geriatric psychopathologies. Physiol. Behav. 102, 115-120.

Ohashi, S., Mori, A., Kurihara, N., Mitsumoto, Y., Nakai, M., 2006. Age-related severity of dopaminergic neurodegeneration to MPTP neurotoxicity causes motor dysfunction in C57BL/6 mice. Neurosci. Lett. 401, 183-187.

Pachana, N.A., McLaughlin, D., Leung, J., Byrne, G., Dobson, A., 2011. Anxiety and depression in adults in their eighties: do gender differences remain? Int. Psychogeriatr. 22 $1-6$.

Park, S.E., Dantzer, R., Kelley, K.W., McCusker, R.H., 2011. Central administration of insulin-like growth factor-I decreases depressive-like behaviour and brain cytokine expression in mice. J. Neuroinflammation 9, 8-12.

Perlovich, G.L., Proshin, A.N., Volkova, T.V., Kurkov, S.V., Grigoriev, V.V., Petrova, L.N. Bachurin, S.O., 2009. Novel isothiourea derivatives as potent neuroprotectors and cog nition enhancers: synthesis, biological and physicochemical properties. J. Med. Chem. $52,1845-1852$.

Pieper, A.A., Xie, S., Capota, E., Estill, S.J., Zhong, J., Long, J.M., Becker, G.L., Huntington, P., Goldman, S.E., Shen, C.H., Capota, M., Britt, J.K., Kotti, T., Ure, K., Brat, D.J. Williams, N.S., MacMillan, K.S., Naidoo, J., Melito, L., Hsieh, J., De Brabander, J. Ready, J.M., McKnight, S.L., 2010. Discovery of a proneurogenic, neuroprotective chemical. Cell 142, 39-51.

Pittenger, C., Duman, R.S., 2008. Stress, depression, and neuroplasticity: a convergence of mechanisms. Neuropsychopharmacology 33, 88-109.

Porsolt, R., Papp, M., 1998. CNS-psychiatric models of disease: depression. In: Enna, S. Williams, M., Ferkany, J., Kenakin, T., Porsolt, R., Sullivan, J. (Eds.), Current Protocols in Pharmacology. Wiley Inc., New York, pp. 591-598.

Porsolt, R.D., Chermat, R., Lenègre, A., Avril, I., Janvier, S., Stéru, L., 1987. Use of the automated tail suspension test for the primary screening of psychotropic agents. Arch. Int. Pharmacodyn. Ther. 288, 11-30.

Pothion, S., Bizot, J.C., Trovero, F., Belzung, C., 2004. Strain differences in sucrose preference and in the consequences of unpredictable chronic mild stress. Behav. Brain Res. 155, 135-146.

Protter, A., Vartiainen, V., Yrjanheikki, J., Bernales, S., 2009. Neurite outgrowth and mitochondrial function in dimebon treated rat cortical cultures. Neurodegener Dis 6 (Abstract 1536).

Rubinow, M.J., Hagerbaumer, D.A., Juraska, J.M., 2009. The food-conditioned place preference task in adolescent, adult and aged rats of both sexes. Behav. Brain Res. 198 263-266.

Schulz, D., Huston, J.P., Buddenberg, T., Topic, B., 2007. "Despair" induced by extinction trials in the water maze: relationship with measures of anxiety in aged and adult rats. Neurobiol. Learn. Mem. 87, 309-323.

Scimonelli, T., Marucco, M., Celis, M.E., 1999. Age-related changes in grooming behaviour and motor activity in female rats. Physiol. Behav. 481-484

Shoji, H., Mizoguchi, K., 2011. Aging-related changes in the effects of social isolation on social behaviour in rats. Physiol. Behav. 102, 58-62.

Skolnick, P., Popik, P., Trullas, R., 2009. Glutamate-based antidepressants: 20 years on. Trends Pharmacol. Sci. 30, 563-569.

Skrinskaia, Iu.A., Nikulina, E.M., 1994. The effect of deprenil on the dopaminergic system of the brain in mice of different genotypes during aging. Zh. Vyssh. Nerv. Deiat. Im. I P Pavlova 44, 842-848.

Snyder, J.S., Soumier, A., Brewer, M., Pickel, J., Cameron, H.A., 2011. Adult hippocampal neurogenesis buffers stress responses and depressive behaviour. Nature. http:// dx.doi.org/10.1038/nature10287.

Sobrian, S.K., Marr, L., Ressman, K., 2003. Prenatal cocaine and/or nicotine exposure produces depression and anxiety in aging rats. Prog. Neuropsychopharmacol. Biol. Psychiatry 27, 501-518.

Soffié, M., Buhot, M.C., Poucet, B., 1992. Cognitive and noncognitive processes involved in selective object exploration: comparison between young adult and old rats. Physiol. Behav. 52, 1029-1035.
Solhaug, H.I., Romuld, E.B., Romild, U., Stordal, E., 2011. Increased prevalence of depression in cohorts of the elderly: an 11-year follow-up in the general population-the HUNT study. Int. Psychogeriatr. 18, 1-8.

Spear, L.P., Varlinskaya, E.I., 2010. Sensitivity to ethanol and other hedonic stimuli in an animal model of adolescence: implications for prevention science? Dev. Psychobiol. 53 , 236-243.

Steru, L., Chermat, R., Thierry, B., Simon, P., 1985. The tail suspension test: a new method for screening antidepressants in mice. Psychopharmacology (Berl) 85, 367-370.

Steru, L., Chermat, R., Thierry, B., Mico, J.A., Lenegre, A., Steru, M., Simon, P., Porsolt R.D., 1987. The automated Tail Suspension Test: a computerized device which differentiates psychotropic drugs. Prog. Neuropsychopharmacol. Biol. Psychiatry 11 659-671.

Strekalova, T., 2008. Optimization of the chronic stress depression model in C57 BL/6 mice: evidences for improved validity. In: Kalueff, A.V., LaPorte, J. (Eds.), Behavoural Models in Stress Research, Volume I. Nova Science Publishers Inc., New York, pp. 111-157.

Strekalova, T., Steinbusch, H., 2009. Factors of reproducibility of stress-induced anhedonia in chronic stress depression models in mice. In: Gould, T. (Ed.), Mood and Anxiety Related Phenotypes in Mice: Characterization Using Behavioural Tests. Humana Press Inc., Totowa, NJ, pp. 153-176.

Strekalova, T., Steinbusch, H.W., 2010. Measuring behaviour with chronic stress depression model in mice. Prog. Neuropsychopharmacol. Biol. Psychiatry 34, 348-361.

Strekalova, T., Spanagel, R., Bartsch, D., Henn, F.A., Gass, P., 2004. Stressed-induced anhedonia in mice is associated with deficits in forced swimming and exploration. Neuropsychopharmacology 11, 2007-2017.

Strekalova, T., Spanagel, R., Dolgov, O., Bartsch, D., 2005. Stressed-induced hyperlocomotion as a confounding factor in anxiety and depression models in mice. Behav. Pharmacol. 16, 171-180.

Strekalova, T. Gorenkova, N., Schunk, E Dolgov, O., Bartsch, D. 2006. Selective effects of citalopram in the mouse model of stress-induced anhedonia with control effects for chronic stress. Behav. Pharmacol. 17, 271-287.

Strekalova, T.V., Cespuglio, R., Koval'zon, V.M., 2008. Depressive-like state and sleep in laboratory mice. Zh. Vyssh. Nerv. Deiat. Im. I P Pavlova 58, 728-737.

Strekalova, T., Couch, Y., Kholod, N., Boyks, M., Malin, D., Leprince, P., Steinbusch, H.W. 2011. Update in the methodology of the chronic stress paradigm: internal control matters. Behav. Brain Funct. 7, 9.

Surget, A., Saxe, M., Leman, S., Ibarguen-Vargas, Y., Chalon, S., Griebel, G., Hen, R. Belzung, C., 2008. Drug-dependent requirement of hippocampal neurogenesis in a model of depression and of antidepressant reversal. Biol. Psychiatry 64, 293-301.

Tokarski, K., Draguhn, A., Gorenkova, N., Dolgov, O., Schunk, E., Kunchulia, M. Steinbusch, H.W.M., Strekalova, T., 2009. Hippocampal LTP in stressed mice with and without hedonic deficit: effects of chronic treatment with citalopram. http:// www.abstractsonline.com/plan/AuthorIndex.aspx?letters=To.

van Miegem, V., Schroeter, C., Cespuglio, R., Pomytkin, I., Valilla, M., Steinbusch, H. Strekalova, T., 2009. Effects of imipramine on depressive-like behaviour and brain peroxidation in $\mathrm{CD} 1$ with a mouse model of stress-induced anhedonia. Behav. Pharmacol. 20 (S1), S61.

Vastola, B.J., Douglas, L.A., Varlinskaya, E.I., Spear, L.P., 2002. Nicotine-induced conditioned place preference in adolescent and adult rats. Physiol. Behav. 77, 107-114.

Vaugeois, J.M., Passera, G., Zuccaro, F., Costentin, J., 1997. Individual differences in response to imipramine in the mouse tail suspension test. Psychopharmacology (Berl) 134, 387-391

Vignisse, J., Steinbusch, H.W.M., Bolkunov, A., Nunes, J., Santos, A.I., Grandfils, C. Bachurin, S., Strekalova, T., 2011. Dimebon enhances hippocampus-dependent learning in both appetitive and inhibitory memory tasks in mice. Prog. Neuropsychopharmacol. Biol. Psychiatry 35, 510-522.

Vignisse, J., Steinbusch, H.W.M. Grigoriev, V., Bettendorf, L, Bolkunov, A., Bachurin, S. Strekalova, T., submitted for publication. Simultaneous and solitary pharmacolog ical manipulation of NMDA- and AMPA-receptors in mice: effects on learning dependent on either glutamate receptor, Neuropharm.

Willner, P., 2005. Chronic mild stress (CMS) revisited: consistency and behaviouralneurobiological concordance in the effects of CMS. Neuropsychobiology 52, 90-110.

Yacoubi, M.E., Popa, D., Martin, B., Zimmer, L., Hamon, M., Adrien, J., Vaugeois, J.M., 2011. Genetic association between helpless trait and depression-related phenotypes: evidence from crossbreeding studies with $\mathrm{H} /$ Rouen and $\mathrm{NH} /$ Rouen mice. nt. J. Neuropsychopharmacol. 3, 1-12.

Zanni, G.R., Wick, J.Y., 2010. Understanding suicide in the elderly. Consult. Pharm. 25, 93-102. 